\title{
PULMONARY STENOSIS WITH NORMAL AORTIC ROOT
}

\author{
BY \\ D. GORDON ABRAHAMS AND PAUL WOOD, Resident Medical Officer, \\ National Heart Hospital, 1934
}

From the Institute of Cardiology and from the Cardiac Department of the Brompton Hospital

Received July 24, 1951

Pulmonary stenosis has always attracted more attention than other forms of congenital heart disease. This was true even in the eighteenth and nineteenth centuries, when the approach to the whole subject was mainly anatomical, and for that reason academic. In recent years the surgical treatment of pulmonary stenosis has inevitably aroused further interest and has underlined the need for more detailed clinical and physiological studies.

Despite this stimulus, there exists today much uncertainty about pulmonary stenosis: disagreement about nomenclature and a proper classification, ignorance of its true incidence, failure to appreciate the great difference between mild and severe cases, unfamiliarity with several of its variations, and, above all, a consistent neglect of physical signs, have all contributed to the confusion.

In this paper we present 71 cases of pulmonary stenosis, occurring either as an isolated lesion or combined with certain other congenital cardiac defects, but excluding the tetralogy of Fallot. Cardiac catheterization was carried out in 55 cases, including all doubtful instances. The diagnosis was further confirmed at necropsy in five and at operation in ten. In all cases great emphasis was placed on careful history taking, detailed physical examination, and comprehensive electrocardiography and radiography. From these studies at least five clear-cut syndromes have emerged, which may be diagnosed at the bedside with a high degree of accuracy. Special techniques are now rarely necessary for practical purposes.

\section{ETIOLOGY}

It is not proposed to discuss the embryology of congenital pulmonary stenosis in detail; this has been thoroughly reviewed by Brown in his recent monograph (1950). It has been suggested that the valvular type is the outcome of fotal endocarditis of the pulmonary cusps after closure of the venticular septum (Abbott, 1927). However, Gross (1941) did not accept this claim because of the lack of any histological evidence of previous inflammation, and because the nature of the endocarditis remained obscure; he suggested that the valvular deformities were due to maldevelopment of the arteries supplying the valves, with consequent infarction and fibrosis. Recently, Gregg (1941), in Australia, has reported a relationship between congenital heart disease in the infant and maternal rubella during the early months of pregnancy, and this has been amply confirmed (Swan et al., 1943; Conte et al., 1945; Miller, 1948; Grönwall and Selander, 1948; and Wesselhoeft, 1949). Wesselhoeft stated that the commonest lesions in such cases were patent ductus arteriosus and ventricular septal defect, and such anomalies indicate that congenital heart disease caused by the rubella virus is due to a maldevelopment rather than to inflammation. Two of the present series of 69 cases of congenital pulmonary stenosis could be attributed to rubella. This low incidence agrees with the general evidence that maternal rubella is a causal factor in only 4 to 5 per cent of all cases of congenital heart disease, although this is ten times the expected frequency if the relationship were coincidental (Conte et al., 1945; Miller, 1948; and Campbell, 1949).

Keith (1909) concluded that infundibular pulmonary stenosis was due to an arrest of the normal involution of the bulbus cordis, which should be incorporated into the right ventricle by the end of the second month. This has received universal agreement. 


\section{NomenClatURE}

Various terms have been used to describe the pulmonary stenosis that is not an integral part of the tetralogy of Fallot. It was termed " pure" by Freed and Budnitz (1946), and by Greene et al. (1949); " isolated" by Mannheimer (1949), Hyman et al. (1951), and Maraist et al. (1951); and " uncomplicated" by Dow et al. (1950). Pulmonary stenosis "with patent foramen ovale" has been identified as a separate syndrome and classified accordingly by Auerbach and Harper (1947) and by Selzer et al. (1949), whilst Adams et al. (1951) write of " pulmonary stenosis with or without interatrial communication." When such a communication is present, either in the form of a septal defect or a patency of the foramen ovale, Joly et al. (1950), in France, employ the eponymous title "the trilogy of Fallot." Bedford and Brown (1937) and Allanby and Campbell (1949) wrote of " pulmonary stenosis with closed interventricular septum." The titles and classification now offered constitute an elaboration of the suggestions made by Wood (1950), and are presented in Table I. The main division serves to separate Fallot's tetralogy and its variants from all other

\section{TABLE I}

\section{Classification and Incidence of Pulmonary Stenosis}

A. Congenital Pulmonary Stenosis with Normal Aortic Root (69 cases)

1. Simple pulmonary stenosis (45 cases).

(A) Valvular (37) and (B) Infundibular (8)

2. Pulmonary stenosis (valvular or infundibular) with arteriovenous shunt (15 cases)

(A) Aorto-pulmonary-P.S. with patent ductus (0)

(B) Interventricular-P.S. with V.S.D. (8)

(C) Interatrial-P.S. with A.S.D. (7)

3. Pulmonary stenosis (valvular or infundibular) with veno-arterial shunt ( 9 cases)

(A) Interventricular-P.S. with reversed interventricular shunt (1)

(B) Interatrial-P.S. with reversed interatrial shunt (8)

B. Congenital Pulmonary Stenosis with Dextroposed or Riding Aorta-Fallot's tetralogy (95 cases)

(A) Valvular or (B) Infundibular

C. Acquired Pulmonary Stenosis (2 cases)

(A) From occlusive disease of pulmonary artery (1) (B) From compression of pulmonary artery (1)

forms of pulmonary stenosis and is based on the origin of the aorta: when this is normal, the aorta arising entirely from the left ventricle, we may speak of pulmonary stenosis with normal aortic root; when the aorta arises partly from the right ventricle it is customary and convenient to use the title Fallot's tetralogy (pulmonary stenosis with riding aorta). Acquired pulmonary stenosis forms a third main group.

There are three main subdivisions of pulmonary stenosis with normal aortic root. The first, simple pulmonary stenosis, may be valvular or infundibular, and implies closed septa. If the foramen ovale happens to be patent (and this may be shown by cardiac catheterization) it must be functionless. Such patency is not academic, because it may alter the subsequent clinical course of the case, particularly if the stenosis is fairly severe. Indeed, there are so many differences between the clinical features of mild and severe cases of simple pulmonary stenosis that the severity should always be indicated in the diagnosis.

The second subdivision includes the cases complicated by a direct left to right shunt through an atrial or ventricular septal defect (possibly through a patent ductus, although this has not yet been encountered in our clinic)*. In such instances the title includes the anatomical lesion present. Thus pulmonary valve stenosis (P.V.S.) with atrial septal defect (A.S.D.) is used to mean that blood is shunting through the defect in the usual direction from left to right. Similarly, infundibular stenosis with ventricular septal defect (V.S.D.) is used to mean pulmonary stenosis (infundibular) with normal aortic root and a left to right shunt through the defect, and not Fallot's tetralogoy:

* With the authors approval, the editor adds that he has recently investigated such a case by cardiac catheterization where the diagnosis was made clinically in 1946. The pressure in the right ventricle was $158 / 10$ and in the pulmonary artery $36 / 16$. The $\mathrm{O}_{2}$ saturation rose from 59 per cent in the right ventricle to 86 per cent in the pulmonary artery. The slight cyanosis was entirèly peripheral (M.C.). 
The third subdivision includes the cyanotic form, in which blood is shunting from right to left through a septal defect. Since uncomplicated septal defects give rise to arterio-venous or left to right shunts, a shunt in the opposite direction may properly be called reversed. The title pulmonary valve stenosis with reversed interatrial shunt thus means that blood is flowing from right to left atrium through a patent foramen ovale or atrial septal defect-it may be impossible to tell which. Pulmonary stenosis with reversed interventricular shunt behaves clinically like Fallot's tetralogy, but the onset of cyanosis may be late or relatively late, and of course the aorta is not over-riding.

\section{INCIDENCE}

Up till quite recently it was often thought that pulmonary stenosis was rare except when it occurred as part of the tetralogy of Fallot. Morgagni (1761) described the first case, and subsequently only sporadic cases have been reported. At intervals these were collected and embodied in treatises on congenital heart disease. Such collections were made by Farre (1814), Gintrac (1824), Peacock (1858), Fallot (1888), and Keith (1909). The latest was that of Maude Abbott (1936) who compiled a report on 1000 cases of all forms of congenital morbus cordis: in this series there were only 25 examples of pulmonary stenosis with normal aortic root. Greene et al. (1949) were able to collect only 68 similar reported cases.

Post-mortem statistics from various centres in the United States confirmed this seeming rarity, and are appended in Table II. Pulmonary stenosis with normal aortic root occurred in only 3

TABLE II

Necropsy Incidence of Pulmonary Stenosis with Normal Aortic Root

\begin{tabular}{|c|c|c|c|c|}
\hline \multirow{2}{*}{ Author } & \multirow{2}{*}{ Date } & \multicolumn{2}{|c|}{ - Total Necropsies } & \multirow{2}{*}{ Percentage } \\
\hline & & $\begin{array}{l}\text { Of Congenital } \\
\text { Heart Disease }\end{array}$ & $\begin{array}{l}\text { Of Pulm. } \\
\text { Stenosis }\end{array}$ & \\
\hline \multirow[t]{2}{*}{$\begin{array}{ll}\text { Leech (Baltimore) } & \\
\text { Dolgopol (New York) } & \ldots \\
\text { McGinn and White (Boston) } & \ldots \\
\text { Terplan and Sanes (Buffalo) } & \ldots \\
\text { Nicholson (Washington) } & \ldots \\
\text { Rannels and Propst (Philadelphia) } \\
\begin{array}{ll}\text { Szypulski (Philadelphia) } \\
\text { Ingham (Mayo Clinic) }\end{array} \\
\begin{array}{l}\text { Gibson and Clifton (Chicago) } \\
\text { Jacobius and Moore (New York) }\end{array} \\
\begin{array}{l}\text { Clawson (Minneapolis) } \\
\text { Cla }\end{array}\end{array}$} & \multirow[t]{2}{*}{$\begin{array}{c}1935 \\
1936 \\
1936 \\
1936 \\
1936 \\
1.937 \\
1937 \\
1938 \\
1938 \\
1938 \\
1944 \\
.\end{array}$} & $\begin{array}{r}75 \\
64 \\
67 \\
21 \\
37 \\
36 \\
13 \\
87 \\
105 \\
131 \\
141\end{array}$ & $\begin{array}{r}5 \\
1 \\
3 \\
2 \\
- \\
1 \\
1 \\
2 \\
6 \\
4\end{array}$ & $\begin{array}{l}6 \cdot 6 \\
1 \cdot 6 \\
4 \cdot 5 \\
9 \cdot 5 \\
- \\
6 \cdot 1 \\
1 \cdot 1 \\
1 \cdot 9 \\
4 \cdot 6 \\
2 \cdot 8\end{array}$ \\
\hline & & 777 & 25 & $3 \cdot 1$ \\
\hline
\end{tabular}

per cent of 777 cases of congenital heart disease. Thus many clinicians were convinced that the lesion was rare. "Pulmonary stenosis is a diagnosis almost certainly wrong, because of the rarity of this affection, which is almost non-existent" (Routier and Escalle, 1943). Taussig (1947) stated that she had never had the opportunity of studying a proven case.

But in 1945 Currens et al. described eleven cases, and doubted this seeming rarity; since then numerous series have been reported (Table III), confirming Currens' view. Thus from 1948 to 1951151 additional cases have been reported, excluding 28 described by Wood (1950) which are embodied in the present series. The exact incidence is difficult to determine, owing to the tendency towards selection in any large series of congenital heart cases. Wood's (1950) figure of 14 per cent was based on a sufficiently unselected series to be close to the true incidence, and this 
TABLE III

' Recent Clinical Reports of Pulmonary Stenosis with Normal Aortic Root

\begin{tabular}{|c|c|c|c|c|c|}
\hline Author & & & & Date & $\begin{array}{c}\text { Cases of P.S. } \\
\text { (normal aortic root) }\end{array}$ \\
\hline 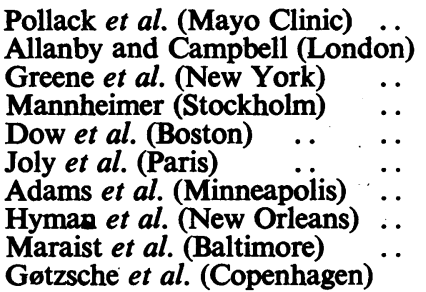 & $\begin{array}{l}\cdots \\
\cdots \\
\cdots \\
\cdots \\
\cdots \\
\cdots \\
\cdots \\
\cdots\end{array}$ & $\begin{array}{l}\cdots \\
\cdots \\
\cdots \\
\cdots \\
\cdots \\
\cdots \\
\cdots \\
\cdots \\
\cdots\end{array}$ & $\begin{array}{l}\cdots \\
\cdots \\
\cdots \\
\cdots \\
\cdots \\
\cdots \\
\cdots \\
\cdots \\
\cdots\end{array}$ & $\begin{array}{l}1948 \\
1949 \\
1949 \\
1949 \\
1950 \\
1950 \\
1951 \\
1951 \\
1951 \\
1951\end{array}$ & $\begin{array}{r}3 \\
8 \\
4 \\
3 \\
8 \\
9 \\
20 \\
3 \\
34 \\
31\end{array}$ \\
\hline
\end{tabular}

tallies fairly well with that of Adams et al. (1951), who found the deformity 20 times in 200 cases, and Gøtzsche et al. (1951) who encountered simple pulmonary stenosis 21 times in 250 catheterizations.

\section{MATERIAL}

The 71 cases comprising this series were seen at the National Heart Hospital, at the Brompton Hospital, or privately over a period of four years ending in July, 1951. Artificial selection, which is more or less inevitable in any specialized clinic, may have influenced the figures, and our present incidence of 80 cases of congenital pulmonary stenosis with normal aortic root ( 9 not included in the series), out of a total of 689 cases of congenital heart disease of all kinds, or 11.6 per cent, may be somewhat too high. On the other hand, the relative incidence of the various types of pulmonary stenosis with normal aortic root, as given in Table $I$, is probably accurate.

For comparison, the number of cases of A.S.D. was $160(23 \%)$; of V.S.D., $100(14.5 \%)$; of patent ductus, $92(13 \%)$; of coarctation of the aorta, $40(6 \%)$; and of Fallot's tetralogy, $95(14 \%)$. There were 526 acyanotic and 163 cyanotic cases. It is believed that the figures for A.S.D. and V.S.D. are too high, for the diagnosis was proved by means of cardiac catheterization in only 47 of the former and 22 of the latter. During the same period, there were 25 patients with a clinical diagnosis of congenital morbus cordis in whom no evidence of such a lesion was found by cardiac catheterization, and of these, 6 had been thought to have A.S.D., and 11 V.S.D.

Age and Sex. The age distribution is set out in Table IV. Nearly 60 per cent were between six and fifteen years old. There were 30 males and 41 females. The slight preponderance of females was seen in every group and subgroup.

\section{Simple Pulmonary Valve Stenosis (Type 1A)}

Of the 37 cases so classified, 19 were mild, 9 moderate, and 9 severe. It is repeated for emphasis that the clinical features of mild cases are very different from those of severe cases, and all shades between the two are seen in the moderate group.

It must suffice at this stage to state that by mild P.V.S. is meant one in which the mean right ventricular pressure does not exceed $25 \mathrm{~mm}$.; in severe cases the mean right ventricular pressure is at least $40 \mathrm{~mm}$. Hg above the sternal angle.

Symptoms. There were no symptoms of any kind in all but two of the mild and moderate cases, and three were notably athletic. Slight effort dyspnœa occurred in the two exceptions, but may not have been due to the cardiac fault, as over-solicitous parents or doctors may induce symptoms.

All the nine severe cases had some degree of dyspncea on effort, slight in three, moderate in two, and considerable in four. One squatted in childhood. Sternal pain occurred on exertion in two cases, one of which also had faintness partly related to effort; and syncope on effort occurred 
TABLE IV

Age Distribution of Pulmonary Stenosis with Normal Aortic Root

\begin{tabular}{|c|c|c|c|c|c|c|}
\hline . & $0-5$ & $6-10$ & $11-15$ & $16-20$ & $21-30$ & $31-42$ \\
\hline $\begin{array}{ccc}\text { Simple (valvular } & \text { and in- } \\
\text { fundibular) } & \ldots & . .\end{array}$ & 7 & 14 & 10 & 6 & 5 & 3 \\
\hline With arteriovenous shunt & $\mathbf{0}$ & 7 & 5 & 3 & $\mathbf{0}$ & 1 \\
\hline 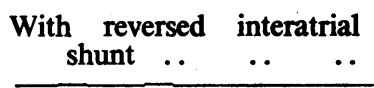 & $\mathbf{0}$ & 2 & 3 & $\mathbf{0}$ & 3 & $\mathbf{0}$ \\
\hline Total & 7 & 23 & 18 & 9 & 8 & 4 \\
\hline
\end{tabular}

in a third. Nevertheless, it was remarkable, on the whole, how little incapacitated most of these patients were.

Two improved greatly after bacterial endocarditis (presumptive in one and proved in the other). Both have been included in the four with considerable effort dyspnœa, but they have remained practically symptom free since their infection ten and four years ago respectively.

Physically two patients were of slight build, while three were unusually robust: normal physique was therefore the rule, which agrees with the findings of Dow et al. (1950). Like Campbell and Reynolds (1949) we found no evidence of intellectual impairment in this series.

Physical Signs. Some writers seem to doubt whether simple pulmonary stenosis can be distinguished clinically from many other acyanotic congenital defects, in particular from patent ductus arteriosus (Ash et al., 1939), from V.S.D. (Mannheimer, 1949), and from A.S.D. (Dow et al., 1950). It has been stated that such distinction is only possible by means of cardiac catheterization.

It is difficult to understand such views, for in our experience an accurate clinical diagnosis is nearly always possible at the bedside, especially with the aid of electrocardiograms and skiagrams. It is felt that the physical signs of pulmonary stenosis cannot be sufficiently known or understood, and therefore they are described here in some detail.

General Appearance. Wood (1950) has called attention to the characteristic facies of severe pulmonary stenosis, which he has termed "bloated" (Fig. 1). With less severe grades of stenosis this bloated or "moon" appearance is not achieved, the face merely appearing full. There is no such facial configuration in mild cases. This trait has been helpful in indicating the severity of the lesion, but we can offer no explanation for the phenomenon.

The difference between the central cyanosis of de Senac (1749) and the peripheral cyanosis of Morgagni (1761) was clearly recognized by Wardrop (1851), and is of fundamental importance. When cyanosis occurs in simple pulmonary stenosis it is always peripheral, never central in origin and neither clubbing of the extremities nor polycythæmia is seen. Peripheral cyanosis, especially on effort, may occur in severe cases, and adds colour to the characteristic moon facies. Even so, it was only observed in five instances.

The Pulse. The volume of the brachial pulse was recorded as small in ten instances, seven of which were severe or relatively severe. In any condition in which the cardiac output is diminished, the pulse pressure tends to be reduced as a result of compensatory peripheral vasoconstriction. In mild cases of pulmonary stenosis the cardiac output is normal and may rise normally on effort (Dow et al., 1950); the pulse is therefore normal. But with severe stenosis the cardiac output tends to be low and fixed, and a small pulse is the rule.

Jugular venous pulse. In simple pulmonary stenosis of severe degree a large $a$ wave was almost constant (Fig. 2), but it did not occur in mild cases and was seen only once in the moderate group. With care and experience it is obvious to the naked eye and its graphic registration is unnecessary. Its presystolic timing is easily recognized by placing a thumb on the opposite carotid artery. When 


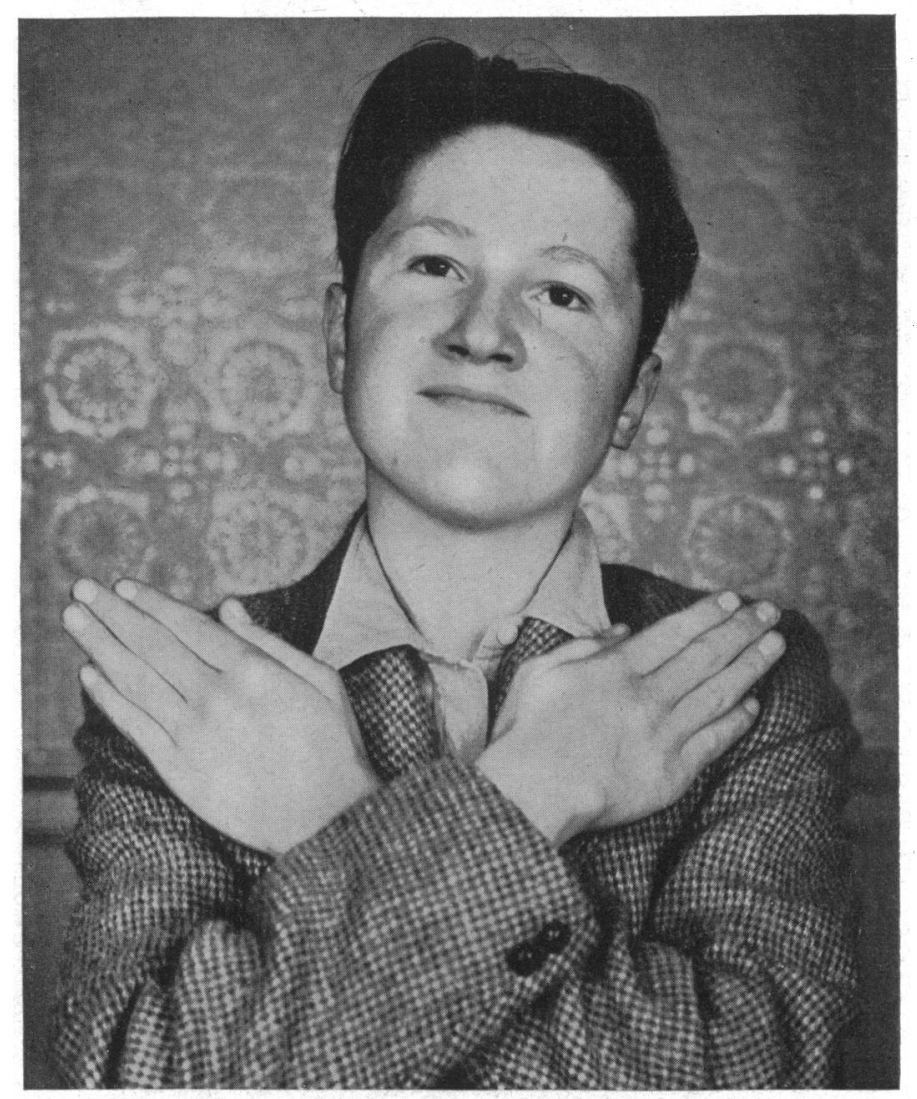

FIG. 1.-Moon facies in severe pulmonary stenosis.

very pronounced, it may be termed a " giant $a$ wave" or venous Corrigan (Wood, 1950). It leaps to the eye, towering above and dwarfing the other waves of the venous pulse, and may be felt as well as seen. An associated presystolic hepatic pulse can usually be detected.

Slight accentuation of the $a$ wave was noted in five mild cases and one moderate case-but its peak was then only one or two cm. higher in the neck than the summit of $v$, and this may occur in several other conditions. Giant presystolic $a$ waves are otherwise only seen in severe pulmonary hypertension and tricuspid stenosis.

Laubry and Pezzi (1913) studied the jugular venous pulse in five cases of congenital heart disease, and noted that the $a$ or auricular wave was exaggerated. They thought that this arose from the efforts of the right atrium to expel its contents against either an increased right ventricular diastolic pressure, or an obstruction at the tricuspid orifice. The latter is certainly the cause of cannon waves in heart block and of large $a$ waves in tricuspid stenosis (McKenzie, 1902).

In four out of six of our cases of severe pulmonary stenosis with giant $a$ waves, the right ventricular pressure at the end of diastole was measured and found to be of the order of 5 to $10 \mathrm{~mm} . \mathrm{Hg}$. above the sternal angle, which, of course, was also the pressure generated by atrial systole. No rise of right ventricular diastolic pressure was found in mild or moderate cases. So the suggestion by Laubry and Pezzi (1913) that the large $a$ wave is due to increased resistance in the right ventricle may well be correct. That giant $a$ waves are not seen in ordinary congestive heart failure does not invalidate this theory, because in heart failure the right atrium has little time to hypertrophy and 


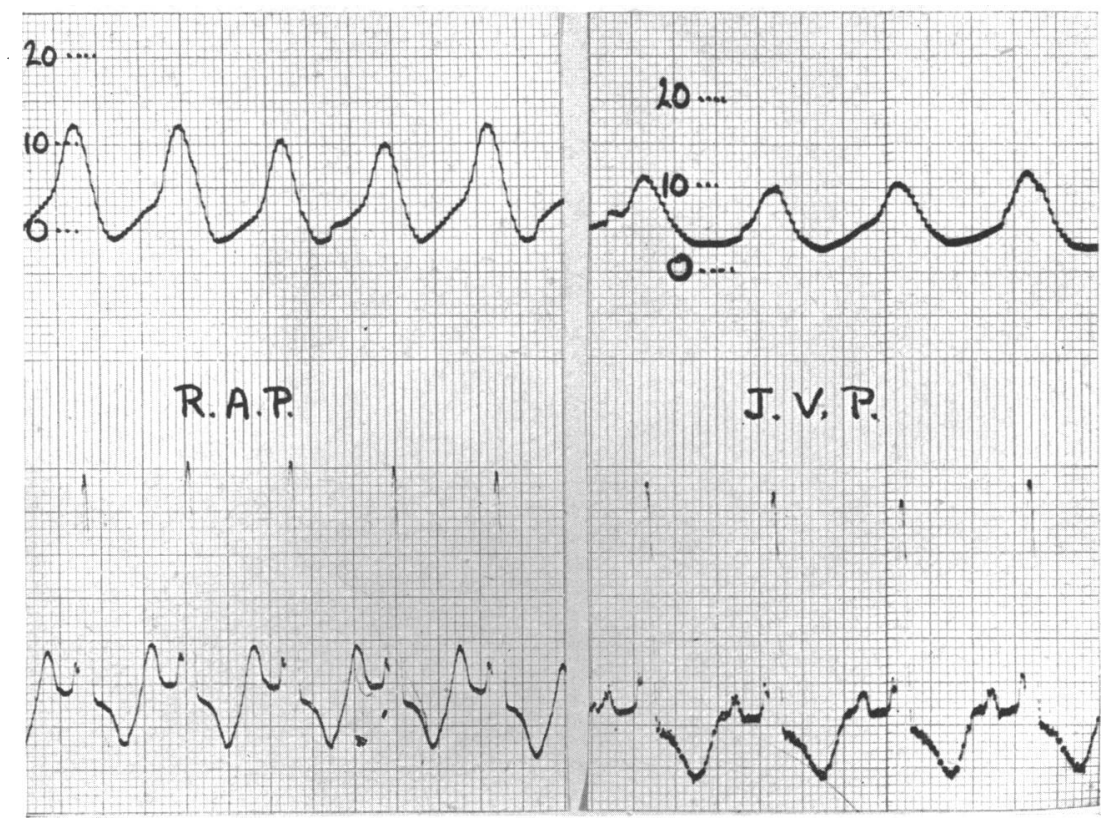

FIG. 2.-Giant $a$ waves in a right atrial pressure tracing from a case of severe pulmonary stenosis.

it may also be weakened by over-distension itself. In two patients with severe pulmonary stenosis, transient nodal rhythm occurred while the right ventricular pressure was being recorded; in both the systolic pressure fell during the period of nodal rhythm(Fig. 3), although there was no appreciable change in heart rate. The difference was far greater than the figure obtained for atrial systole itself. This shows clearly that strong right atrial contraction in presystole helps the right ventricle to generate a high systolic pressure. This is probably an example of Starling's law of the heart, strong atrial systole augmenting late diastolic distension of the right ventricle so that that chamber contracts more forcibly.

The Cardiac Impulse. The normal cardiac impulse is, of course, a left ventricular systolic event. When the left ventricle hypertrophies, the impulse becomes more sustained, and thrusting or heaving in character-the choc en dôme of French writers-and at the same time there may be visible retraction of the soft tissues between the ribs medial to it. When the right ventricle enlarges, it displaces the left backwards away from the anterior chest wall and comes to occupy most of the anterior cardiac surface. This modifies the cardiac impulse; the left ventricular thrust disappears, and at the apex of the heart only a tap, representing the first heart sound, can be felt. The hypertrophied right ventricle causes instead a visible and palpable lift or heave in the third and fourth intercostal spaces between the sternal border and the mid-clavicular line (Laubry and Pezzi, 1921). When very pronounced, this right ventricular lift may be felt right over as far as the apex beat, where it may be mistaken for a left ventricular thrust.

The degree of right ventricular hypertrophy in pulmonary stenosis depends upon the severity of the stenosis. In mild cases, enlargement is slight or negligible, and may be insufficient to modify the character of the cardiac impulse. Thus, of the 19 mild cases, a normal left ventricular cardiac impulse was felt in no less than twelve, and there was no right ventricular lift in nine of them. When the lift was present it was only slight in degree.

In contrast, a normal left ventricular cardiac impulse could not be felt in any of the moderate or - severe cases; in all but three it was replaced by the tap of the first heart sound, and in the three exceptions a gross right ventricular heave extended right across from the sternal border to the apex 


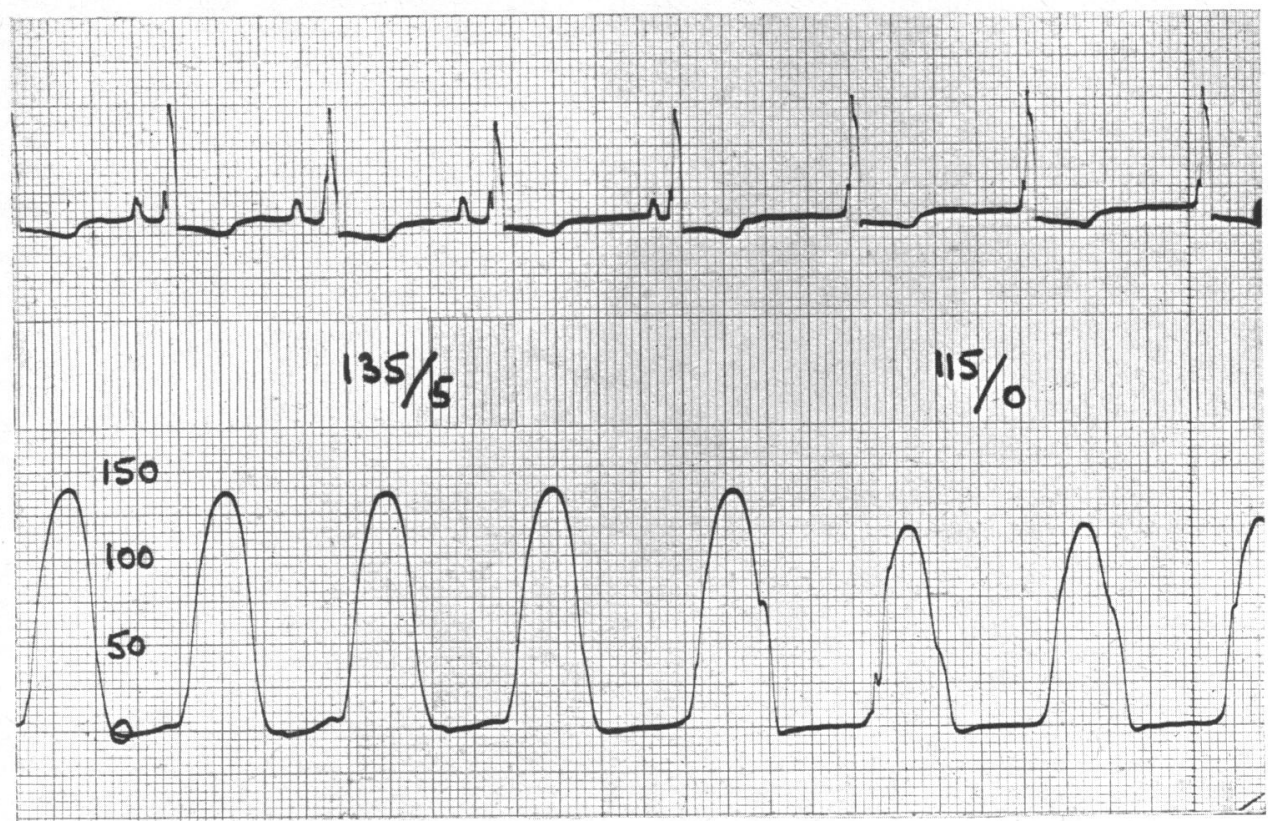

FIG. 3.-The effect of transient nodal rhythm on the right ventricular systolic pressure in a case of severe pulmonary stenosis with giant $a$ waves.

beat. The right ventricular lift was very pronounced in six of the severe, and considerable in two of the moderate cases.

Pulsation in the Pulmonary Area. It is common knowledge that a raised pressure in the pulmonary artery or an increased blood flow through the lesser circulation may give rise to a visible or palpable systolic impulse over the pulmonary artery in the second left intercostal space at the sternal border. In pulmonary stenosis the pressure in the pulmonary artery is normal or reduced, and the blood flow normal or diminished. Consequently, no such pulsation is to be expected in this region, despite the presence of a dilated pulmonary artery; in fact, absence of pulsation over the pulmonary artery has proved an almost inviolate rule in congenital pulmonary stenosis. There was only one exception, a mild case with a thin chest wall and normal pulmonary artery pressure.

The Systolic Thrill. One of the classical physical signs of pulmonary stenosis is a systolic thrill in the pulmonary area. Indeed, the thrill and murmur are the only physical findings recorded by some writers. A thrill was present in every case in this series, except two with very mild lesions. In two others, the thrill was very faint and was only obvious after exercise, but in the vast majority it was easily felt; indeed, the clinical diagnosis of pulmonary stenosis with normal aortic root is hardly tenable in its absence. The thrill was usually best appreciated high up over the pulmonary artery in the second left intercostal space at the sternal border, but in four cases it was equally intense in the third space, and in two others it was distinctly low, being maximal in the third and fourth spaces. In one of these, simple tight valve stenosis was proved by catheterization, operation, and necropsy; in the other by catheterization only. As will be seen later, a really low thrill usually means infundibular stenosis or associated V.S.D.

The intensity of the thrill appeared to bear some relationship to the severity of the lesion, all those with faint thrills ( 5 cases) having mild stenosis, and the four with especially gross thrills having severe (3) or moderate (1) stenosis. Conversely, all the 18 severe and moderate cases had well marked thrills.

The Murmur of Pulmonary Stenosis. There has been no case of pulmonary stenosis recorded 
without a systolic murmur in the pulmonary area. It is commonly described as loud or harsh; it is usually maximal in the second space to the left of the sternum, but may be widely distributed when loud. Some observers have emphasized that it is not well heard in the neck, and in general this has been our experience.

Dow et al. (1950) studied the phonocardiogram in three of their cases of pulmonary. stenosis, and reported that the murmur was diamond-shaped, although this feature was neither uniform nor pathognomonic. Leatham (1951) has shown that the murmur of aortic stenosis has this characteristic, and it would not be remarkable if the two murmurs were similar in this respect.

A pulmonary diastolic murmur was heard in only one case in this series, and that after bacterial endocarditis. However, a pulmonary diastolic murmur was recorded in a case of pulmonary stenosis by Dow et al. (1950), and also by Hyman et al. (1951): the first of these was very mild and complicated by V.S.D.; the second was not proved. In our experience a pulmonary diastolic murmur invalidates the diagnosis of uncomplicated pulmonary stenosis, and strongly favours A.S.D., pulmonary hypertension, or idiopathic dilatation of the pulmonary artery.

The Heart Sounds. Physical examination is completed by careful auscultation of the heart sounds. Presystolic gallop is not uncommon in severe cases, the auricular sound presumably arising from the right side of the heart. Laubry and Pezzi (1921) emphasized that this auricular sound is well heard over the neck veins.

There was nothing remarkable about the first heart sound in any of our cases. It was neither unduly split nor accentuated, even in severe cases. This harmonizes with the current belief that the intensity of the first sound depends far more upon the position of the mitral and tricuspid leaflets at the onset of ventricular systole, than upon the strength of ventricular contraction. It has already been shown that powerful atrial contraction raises the right ventricular end diastolic pressure to an unusual degree in severe pulmonary stenosis, and if atrial relaxation precedes ventricular systole, the tricuspid valve must close before the first heart sound.

There is still some confusion about the second heart sound in pulmonary stenosis. Bedford and Brown (1937) concluded that it was usually diminished and this was confirmed by Love (1937) and by Hyman et al. (1951). Dow et al. (1950) reported on the "pulmonary second sound" in six of their eight cases. It was increased in three, and of normal intensity in the other three. From a study of the reported cases and of two of their own with reversed interatrial shunts, Selzer et al. (1949) thought that the intensity of the " pulmonary second sound " was of limited diagnostic value. Gøtzsche et al. (1951) found the " second pulmonic sound was usually stronger than the second aortic sound ... thus a faint pulmonic second sound is not the rule."

These discordant views have arisen from failure to appreciate the normal character and constitution of the second heart sound, with consequent lack of precision in describing what is actually heard in pulmonary stenosis. . The second heart sound is caused by closure of the aortic and pulmonary valves, and it has been known for at least a century that these may close asynchronously and give rise to splitting of this sound. Such splitting is normal, and occurs in about 90 per cent of children and young adults in perfect health, and can be heard best in the pulmonary area. Respiration modifies the degree of splitting, which becomes appreciably wider on deep inspiration. Samuel Gee (1893) credits Schafer (1859) with this original observation.

The phonocardiogram affords presumptive evidence that the second element of this split is caused by pulmonary valve closure in most, if not in all, cases (Leatham, 1951). In right bundle branch block there is delayed activation of the right ventricle, and consequently the second sound becomes more widely split. It has become customary to classify splitting of the second sound into four grades according to the width of the split-the widest being in grade four. Normal splitting is grade one or two. In the neck, in the second right intercostal space, and at the apex beat, only a single second heart sound, the aortic, can normally be heard.

With application and experience, the intensity of each of the two components of the second heart sound in the pulmonary area can be assessed. They are normally of equal intensity, but with hypertension in the lesser circulation the second or pulmonary element is accentuated, and 
with pulmonary hypotension it is diminished or inaudible. There is also some evidence that a high pulmonary diastolic pressure tends to cause relatively early closure of the pulmonary valve so that the split is close (grade 1); and that a low pulmonary diastolic pressure delays pulmonary valve closure, so that the split (if heard at all) may be wide (grade 3 ).

The behaviour of the second heart sound in pulmonary stenosis tallies with these general principles. All the severe and moderate cases had single second heart sounds at the pulmonary area. The intensity of this sound, which is aortic, is irrelevant. Of the 19 mild cases, only seven had a single second heart sound; in the other twelve the sound was obviously split (grade 2), widely so (grade 3) in two instances. The second or pulmonary element was of normal intensity in six (Fig. 4), and unduly soft in six.

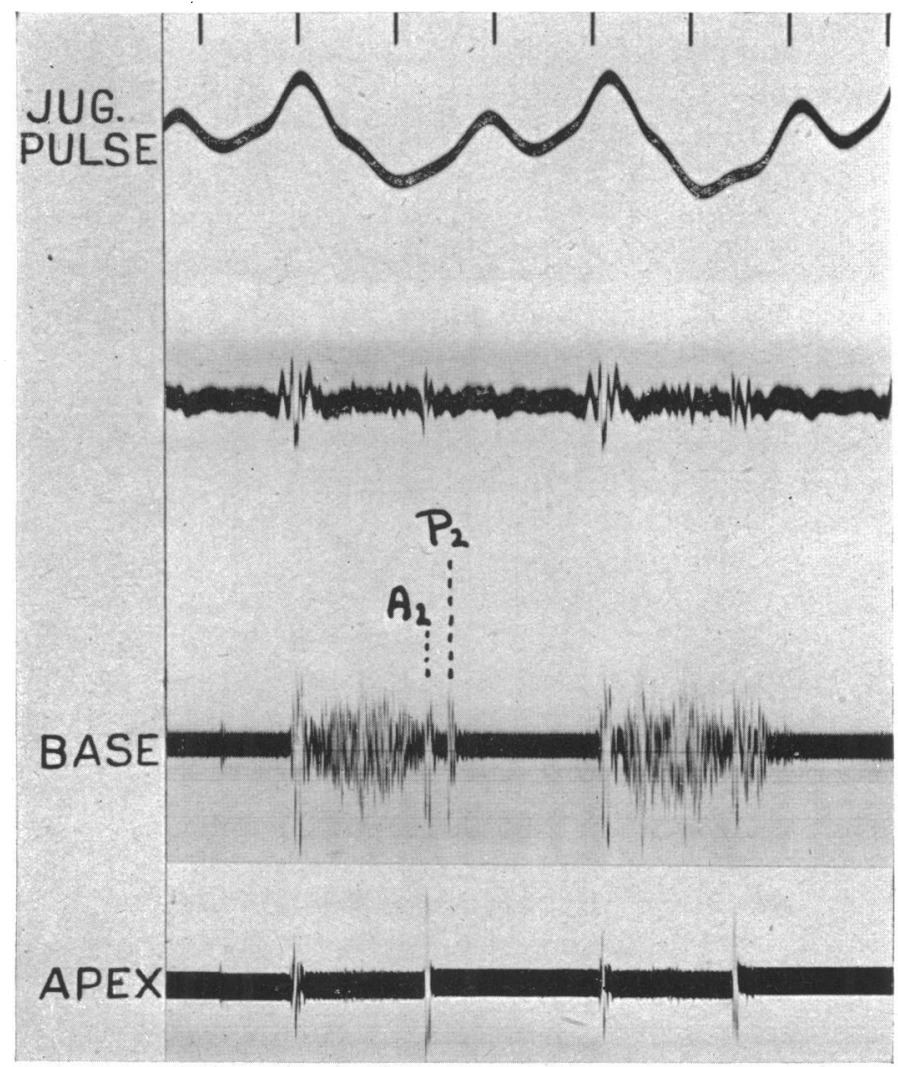

Fig. 4.-Phonocardiogram from a case of mild pulmonary stenosis showing a split second heart sound at the pulmonary area and a pulmonary element of normal intensity in relation to the aortic. (From the Cardiac Dept. of the London Hospital).

$X$-Ray Appearances. There are three important radiological features of pulmonary stenosis: post-stenotic dilatation of the main pulmonary artery; diminution in the pulmonary vascular markings; and enlargement of the right heart.

All workers are unanimous that post-stenotic dilatation of the pulmonary artery is a very constant feature of simple P.V.S., and there were no exceptions in our series. This dilatation affects the pulmonary trunk, and occasionally its right and left branches, but is not distributed further down the vascular tree (Fig. 5). In rare instances it is aneurysmal, and in one of Seltzer's reported 


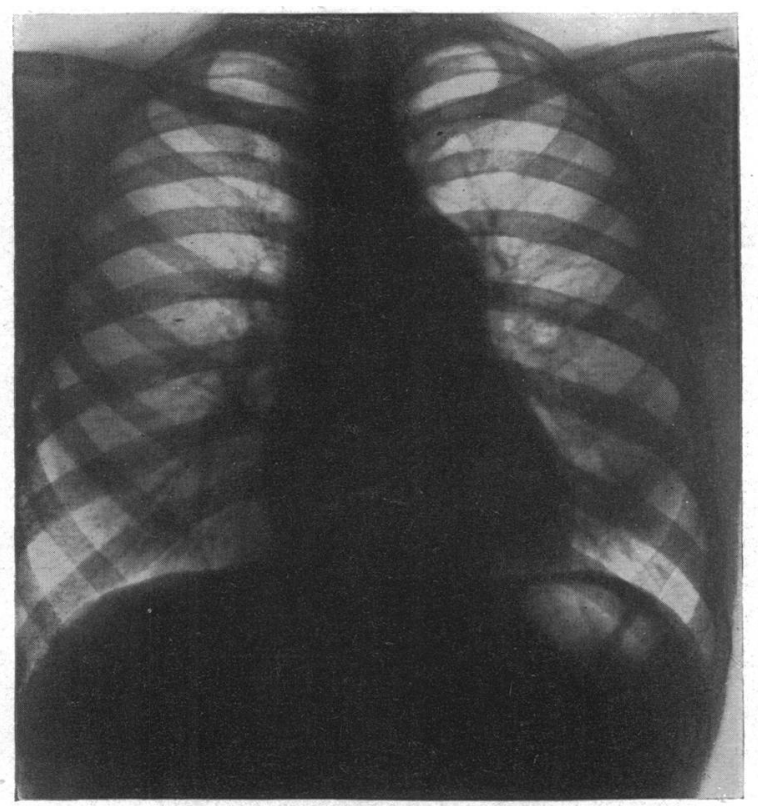

Fig. 5.-Dilated pulmonary trunk and normal vascular markings in a case of mild pulmonary valve stenosis.

cases (1949), it was mistaken for a lung tumour. Only one of our patients had aneurysmal dilatation of the pulmonary artery, and in him both main branches were also involved.

In our series there was no correlation between the degree of dilatation of the pulmonary artery and the severity of the stenosis. Dilatation was usually slight or moderate, and rarely reached the extreme proportions sometimes encountered in A.S.D., V.S.D., and patent ductus. Pulsation appeared to be normal, and a hilar "dance" was never seen.

According to Bedford and Brown (1937), post-stenotic dilatation of the pulmonary artery was first described radiologically by Usumoto (1925), though noted at necropsy many years previously. There has been much speculation concerning its origin. Paul (1871) collected 27 reported cases of acquired pulmonary stenosis, and maintained that the pulmonary artery was then involved in the same inflammatory process as the valve; if congenital pulmonary stenosis was due to valvulitis in utero, associated pulmonary arteritis could be assumed. Potain and Rendu (1875) agreed, and thought that endarteritis caused a loss in elasticity of the pulmonary artery with subsequent dilatation. Against this was a considerable body of opinion which invoked a distinct congenital defect in the wall of the vessel. However, in 1915 Cavina produced pulmonary stenosis experimentally in rabbits by ligating the pulmonary artery at its source, and he reported that dilatation of the pulmonary artery distal to the stricture occurred consistently in all animals that survived. It seems probable, therefore, that the dilatation is a natural mechanical outcome of the stenosis.

The vascular shadows in the lungs are a direct expression of the amount of blood held in various parts of the pulmonary circulation. In severe P.V.S. pulmonary blood flow is strictly limited and may be below normal even at rest; the vascular markings are then reduced in number and size (Fig. 6). Pulmonary ischæmia of this kind was seen in all our severe cases, and in three of our moderate cases. Because of the restricted left ventricular output, and the dilated pulmonary artery, the aorta appears relatively small. It must be stressed, however, that with mild pulmonary stenosis, there is little or no reduction in pulmonary blood flow, and the vascular markings in the lungs remain normal (Fig. 5). Thus pulmonary ischæmia was seen in none of our mild cases.

Finally, in moderate and severe pulmonary stenosis enlargement of both the right atrium and right ventricle becomes apparent radiologically (Fig. 6); this is not seen in mild cases. Like Brock and Campbell (1950) we find that the aortic arch is left-sided in simple pulmonary stenosis. 


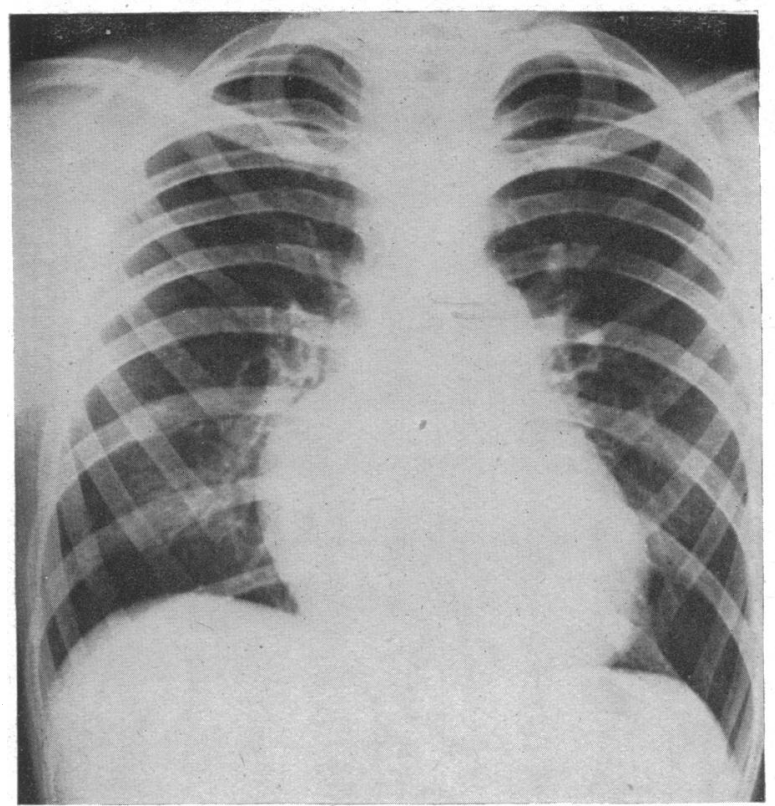

FIG. 6.-Dilated pulmonary trunk, pulmonary ischæmia, and enlargement of the right atrium and ventricle in a case of severe pulmonary valve stenosis.

The Electrocardiogram

In simple pulmonary stenosis this records all degrees of right ventricular hypertrophy, and in the very mild cases it is entirely normal. It is important to distinguish right ventricular hypertrophy from right axis deviation - the latter term of course simply describes the electrical position of the heart. Gøtzsche et al. (1951) reported right axis deviation in only 11 of their 21 cases, and stated that otherwise the cardiogram was normal. Right axis deviation occurred in every one of our series.

In the present analysis (Table V) cardiographic evidence of right ventricular hypertrophy was divided into four grades, according to unipolar chest lead appearances (Fig. 7).

(1) Slight: $R$ and $S$ about equal in amplitude in lead V1.

(2) Moderate: $\mathrm{R}$ dominant in lead V1, but $\mathrm{S}$ still present.

(3) Severe: $R$ wave tall in lead V1, S. small or absent, and T usually inverted.

(4) Similar to grade 3, but appearances extending across the chest to at least lead V3, usually to V4 or even to V5.

It will be seen from Table $\mathrm{V}$ that normal curves only occurred in mild cases, and that grade 4 right ventricular hypertrophy occurred only in severe cases. Similarly, the P wave was normal in all but one of the mild cases, and the well developed $\mathbf{P}$ pulmonale was almost confined to severe cases. A pointed $\mathbf{P}$ wave measuring about $2 \mathrm{~mm}$. in amplitude, and moderate to considerable right ventricular preponderance, were characteristic of cases in the moderate group.

Right bundle branch block was recorded by Blackford and Parker (1941) in a case of simple pulmonary stenosis, and an incomplete right branch block pattern, QRS never exceeding $0.10 \mathrm{sec}$., was seen in seven cases in the present series (19\%). Barber et al. (1950) reported its occurrence in 95 per cent of cases of atrial septal defect, an incidence amply confirmed by subsequent cases investigated at this Institute. The presence or absence of the right branch block pattern is therefore helpful in differential diagnosis, but is not conclusive.

\section{Summary of Clinical Features}

The mildest cases of simple pulmonary valve stenosis have no symptoms, are capable of heavy physical effort, and look healthy. The peripheral pulse and jugular venous pressure are normal. The cardiac impulse is normal and left ventricular in' type. There is a high systolic murmur 
TABLE V

Electrocardiographic Analysis of Simple Pulmonary Stenosis

\begin{tabular}{|c|c|c|c|c|}
\hline & & $\begin{array}{c}\text { Mild } \\
(19 \text { cases })\end{array}$ & $\begin{array}{l}\text { Moderate } \\
\text { (9 cases) }\end{array}$ & $\begin{array}{c}\text { Severe } \\
(9 \text { cases })\end{array}$ \\
\hline 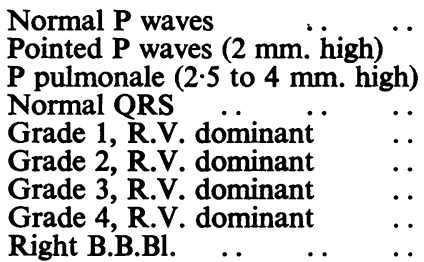 & 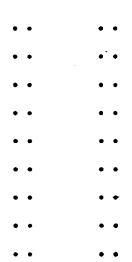 & $\begin{array}{r}18 \\
0 \\
1 \\
8 \\
2 \\
2 \\
1 \\
0 \\
6\end{array}$ & $\begin{array}{l}5 \\
4 \\
0 \\
0 \\
2 \\
2 \\
5 \\
0 \\
0\end{array}$ & $\begin{array}{l}3 \\
2 \\
4 \\
0 \\
0 \\
0 \\
2 \\
6 \\
1\end{array}$ \\
\hline
\end{tabular}

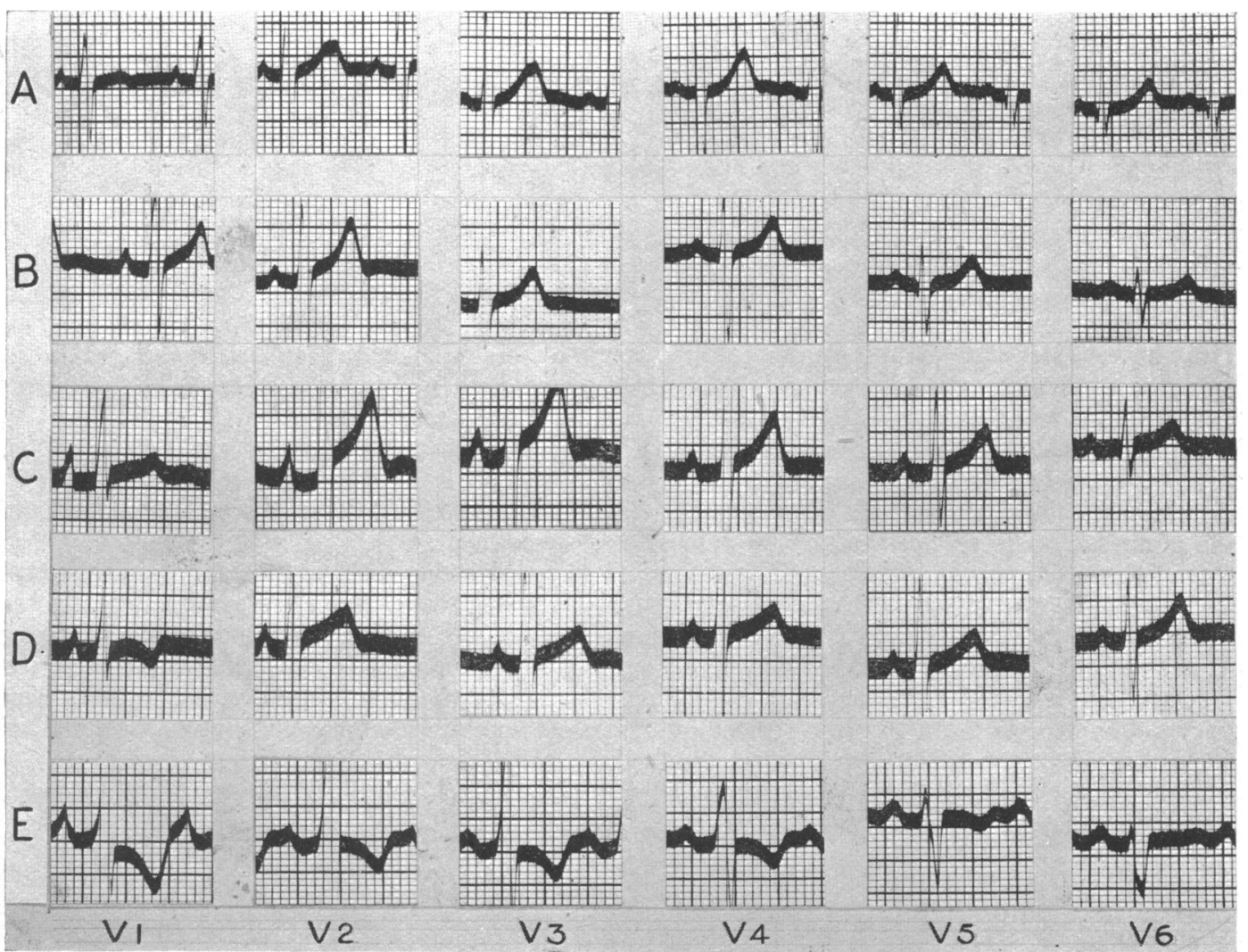

FIG. 7.-Chest lead electrocardiograms (V1 to V6) from five cases of simple pulmonary valve stenosis showing increasing grades of right ventricular preponderance from none $(A)$ to grade $4(E)$.

and thrill over the pulmonary artery maximal in the second left intercostal space. The second heart sound at the pulmonary area is normally split, and the second or pulmonary element is of normal intensity. X-rays show no cardiac enlargement, and normal pulmonary vascular shadows, but the pulmonary trunk itself is dilated. The electrocardiogram is usually normal. 
In slightly less mild cases the cardiac impulse becomes tapping at the apex beat, and a right ventricular parasternal lift develops. Pulmonary artery pulsation is impalpable. The second heart sound may still be split, but the pulmonary element is softer. The electrocardiogram shows evidence of right ventricular hypertrophy (grades 1 or 2 ).

In cases of moderate severity, the face may look full, the radial pulse is a little small, and a dominant $a$ wave appears in the neck. The parasternal lift is more conspicuous, and the second heart sound is single. X-rays may show slight enlargement of the right side of the heart, and the pulmonary vascular markings may be rather light. The electrocardiogram usually shows a pointed $P$ wave about $2 \mathrm{~mm}$. high, and right ventricular dominance is moderate or considerable.

Severe cases have some degree of effort intolerance, and may complain of dyspnca, pain, or faintness. The face is often bloated and there may be peripheral cyanosis. The radial pulse is small, a giant $a$ wave appears in the neck, and the liver may pulsate in presystole. The right ventricular parasternal lift is very impressive and may extend unusually far to the left. The second heart sound is always single. $\mathrm{X}$-rays show considerable enlargement of the right atrium and ventricle, and there is pbvious pulmonary ischæmia. The electrocardiogram shows a well developed $\mathbf{P}$ pulmonale and evidence of considerable or gross right ventricular preponderance.

The only findings in common between mild and severe cases are the systolic thrill and murmur, and the dilated pulmonary artery.

\section{Differential Diagnosis}

Although properly trained observers have made few mistakes in the clinical diagnosis of simple pulmonary stenosis, the general tendency has been otherwise. The commonest error has been to mistake pulmonary stenosis for the maladie de Roger or for A.S.D. There are several reasons for this. First is the failure to appreciate that simple pulmonary stenosis may be a very mild lesion, with little or no evidence of right ventricular hypertrophy, clinically or electrocardiographically. Second is the ignorance surrounding the nature and behaviour of the second heart sound, especially perhaps of the fact that normal splitting is the rule in mild stenosis. Third is the mistaken view that the lesion is rare, so that the diagnosis is too often made with reluctance - a view exaggerated by the persistent belief that a small V.S.D. (maladie de Roger) is the commonest form of acyanotic congenital heart disease. Such a defect is rare indeed (Wood, 1950), most cases of V.S.D. resulting in sufficient shunt to cause a hyperdynamic left ventricle and obvious pulmonary plethora. The rare mild case, with nothing but a low thrill and murmur may be confused with mild infundibular stenosis (vide infra), but the low position of the thrill, and the absence of dilatation of the pulmonary artery, together exclude pulmonary valve stenosis.

Atrial septal defect may be suggested by the combination of a right-sided lesion, splitting of the second heart sound, and dilatation of the pulmonary artery. But in A.S.D. the cardiac impulse though right ventricular in type, is more tumultuous or hyperdynamic due to overfilling of the right ventricle; the second heart sound in the pulmonary area is more widely split, and the pulmonary component is normal or accentuated, never absent or soft; a pulmonary diastolic murmur or an apparent mitral diastolic murmur may be heard; pulmonary plethora is always seen radiologically, and pulsation extends well down the main branches; and right bundle branch block is almost constant. Finally, it is being gradually realized that a pulmonary systolic thrill is not at all common in uncomplicated A.S.D., and should at once suggest pulmonary stenosis, alone or associated with A.S.D.

Idiopathic dilatation of the pulmonary artery has occasionally been confused with simple pulmonary stenosis. This was first described by Cossio (1937) and since then has been studied in some detail, especially by French workers. The proof that other lesions, known to cause enlargement of the pulmonary artery, were absent in these cases, was not always forthcoming; it is possible that some were in fact examples of pulmonary stenosis or A.S.D. Greene et al. (1949) have recently reported four examples of this lesion and consider that the diagnosis can only be made by means of cardiac catheterization; they state that the pulmonary artery pressure is low, but that in the right ventricle the pressure is normal, in contrast to the raised pressure in pulmonary stenosis. Necropsy proof of the absence of stenosis in such cases would be more convincing.

We have had the opportunity of studying two cases of gross idiopathic dilatation of the pulmonary artery with pulmonary incompetence; the pressures in the pulmonary artery and right ventricle were entirely normal in both. 
Real difficulty is sometimes experienced when a normal subject presents with a pulmonary systolic murmur and apparent dilatation of that vessel (Fig. 8). The absence of a thrill, even after exercise, prevents error. Normal pressures in the pulmonary artery and right ventricle, and no intracardiac shunt, were found on cardiac catheterization in seven such cases.

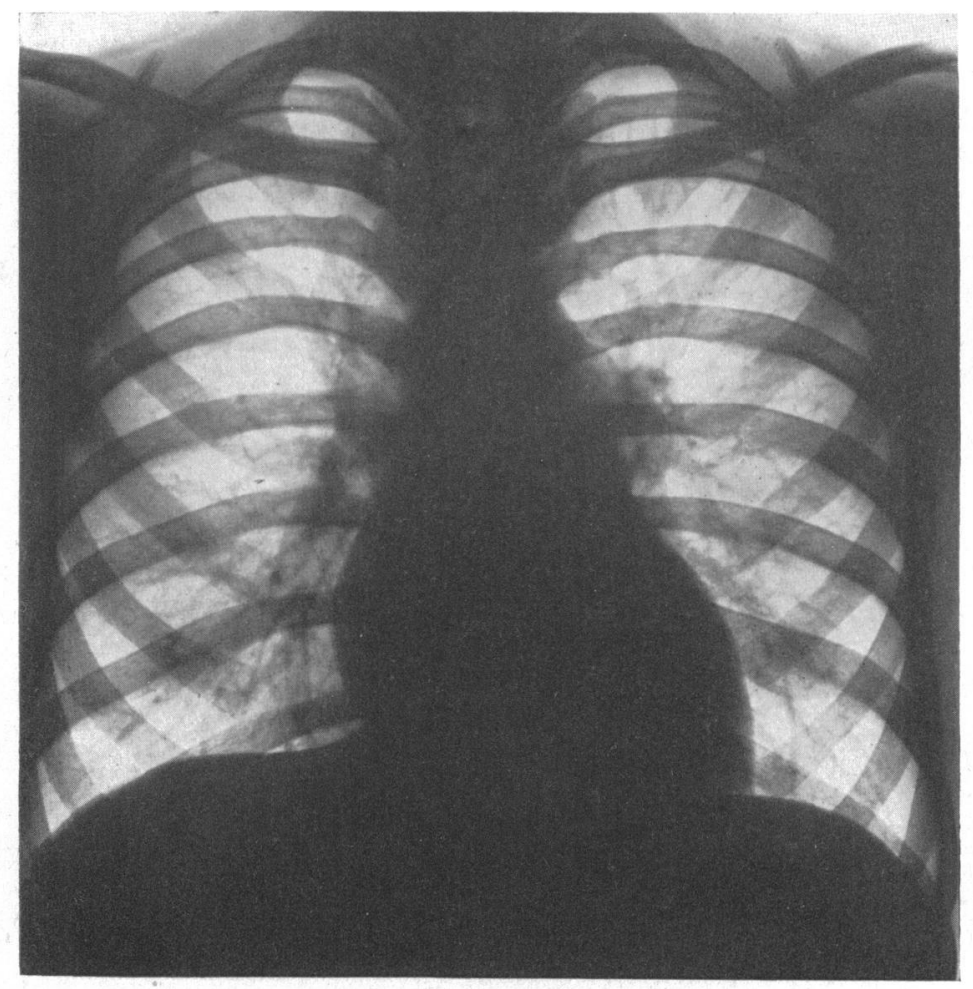

FIG. 8. -Dilatation of the pulmonary artery in a normal subject.

Physiological Studies in P.V.S.

Cardiac catheterization was carried out in 26 of the 37 cases of simple P.V.S.; in the other 11 the diagnosis was obvious, and for a variety of reasons the investigation was omitted or deferred. All doubtful cases, and all those in which expert opinion as to diagnosis differed, were either catheterized or excluded from the series. Pressures were recorded by means of a saline manometer in the earlier, and by means of a Sanborn electrical manometer and direct writing polyviso in later cases. The findings may be very simply expressed (Table VI).

(1) The systolic and mean pressures in the right ventricle were always much higher than those in the pulmonary artery.

(2) In mild cases the right atrial pressure was normal, the right ventricular systolic pressure 30 to $50 \mathrm{~mm}$. $\mathrm{Hg}$ (mean, 11 to $25 \mathrm{~mm}$.), and the mean pulmonary artery pressure 5 to $11 \mathrm{~mm}$. The mean right ventricular pressure was consistently two to three times the mean pulmonary artery pressure.

(3) In moderate cases the right atrial pressure was usually normal, but the $a$ wave in the pressure tracing was sometimes accentuated (around $5 \mathrm{~mm}$. $\mathrm{Hg}$.). The right ventricular systolic pressure was 51 to 100 with a mean pressure between 26 and $40 \mathrm{~mm}$. $\mathrm{Hg}$. The mean pulmonary artery pressure was 5 to $10 \mathrm{~mm}$, being three to five times lower than the mean right ventricular pressure.

In the severe cases the right atrial systolic pressure usually measured about $10 \mathrm{~mm}$., the tracing $2 \mathrm{M}$ 
TABLE VI

Findings on Cardiac Catheterization

\begin{tabular}{|c|c|c|c|c|c|c|c|}
\hline & & & & \multirow{2}{*}{$\begin{array}{c}\text { Right } \\
\text { Atrial } \\
\text { Pressure } \\
(\mathbf{m m} . \mathbf{H g})\end{array}$} & \multicolumn{2}{|c|}{$\begin{array}{c}\text { Right } \\
\text { Ventricular } \\
\text { Pressure } \\
\text { (mm. Hg) }\end{array}$} & \multirow{2}{*}{$\begin{array}{c}\begin{array}{c}\text { Pulmonary } \\
\text { Artery } \\
\text { Pressure } \\
\text { (mm. Hg) }\end{array} \\
\text { Mean }\end{array}$} \\
\hline & & & & & sys/dias. & Mean & \\
\hline $\begin{array}{l}\text { MILD } \\
\text { (16 cases) }\end{array}$ & . & .. & .. & normal & $\frac{30-50}{0}$ & $11-25$ & $5-11$ \\
\hline $\begin{array}{l}\text { MODERATE } \\
(3 \text { cases })\end{array}$ & . & $\cdots$ &.. & $\begin{array}{c}\text { normal } \\
(a \text { wave up to } 5 \mathrm{~mm} .)\end{array}$ & $\frac{51-100}{0}$ & $26-40$ & $5-10$ \\
\hline $\begin{array}{l}\text { SEVERE } \\
\quad(7 \text { cases) }\end{array}$ & $\cdots$ & $\cdot \cdot$ & .. & $\frac{9-16}{-5 \text { to }+6}$ & $\frac{125-175^{*}}{0-11}$ & $\begin{array}{c}\text { over } \\
40\end{array}$ & $\stackrel{4}{2-10}$ \\
\hline
\end{tabular}

* Over 100 usually higher than systemic pressure.

showing characteristic giant $a$ waves (Fig. 2). The right ventricular systolic pressure ranged between 125 and $175 \mathrm{~mm}$. $\mathrm{Hg}$, and was usually higher than the systemic blood pressure. The mean right ventricular pressure ranged between 44 and $67 \mathrm{~mm}$., and was always at least five times higher than the mean pressure in the pulmonary artery, which lay between 2 and $10 \mathrm{~mm}$. A typical tracing is shown in Fig. 9.

No difficulty was experienced in entering the pulmonary artery in these cases, but a small catheter (No. 6) was used in the most severe cases, in fear that a larger one might obstruct the circulation at the valve orifice. In fact, no change in the patient's condition was ever noticed as the catheter passed through the valve.

The catheter passed through a probe-patent foramen ovale in three of these acyanotic cases, and samples from both sides of the heart revealed no shunt in either direction. The left atrial pressure was 2 or $3 \mathrm{~mm}$. higher than the right, so the flap-valve would remain shut. Only when the stenosis is severe enough to raise the right and lower the left atrial pressure is a reversed interatrial shunt possible. This is discussed later under that heading.

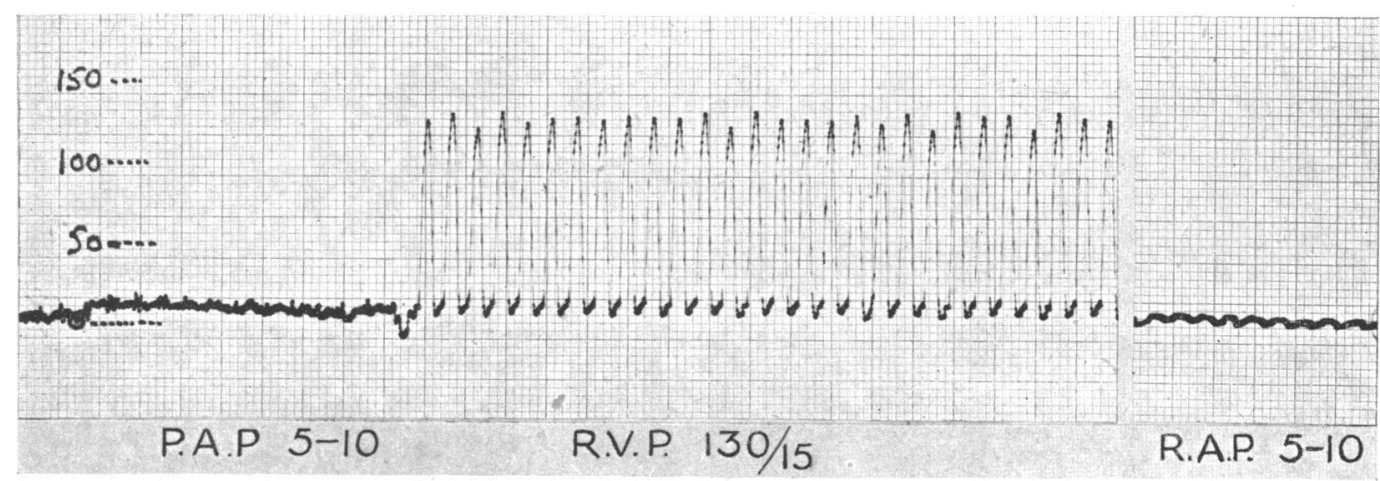

Fig. 9.-Pressure tracings from the pulmonary artery, right ventricle, and right atrium in a case of severe pulmonary valve stenosis. 
The cardiac output at rest was normal in mild and moderate cases, but was rather low ( 3 to 4 $\mathrm{L} / \mathrm{min}$.) in all the severe cases. The arterio-venous oxygen difference provided a sharper distinction between mild and severe cases, for it ranged between 21 and $50 \mathrm{ml}$./L. (average 36) in the mild group and between 53 and 83 (average 66) in the severe group. Dow et al. (1950) have shown that the output may also rise normally on effort in mild cases, but may be fixed in severe cases; a considerable rise in right ventricular systolic pressure is associated with any increase or attempted increase in output.

The arterial oxygen saturation was normal (93 to $96 \%$ ) in all cases, including the most severe, and including three cases in which the catheter passed through a valvular patency of the foramen ovale. Haldane's method was used for all gas analysis.

\section{Simple Infundibular Stenosis (Type 1B)}

In this condition there is some interference with the normal process whereby the bulbus cordis is incorporated into the right ventricle. Consequently this structure persists as a separate chamber divided from the body of the right ventricle by a fibrous ring which obstructs the outflow tract of the right ventricle. The pulmonary valve may be normal or it may also be stenosed.

Infundibular stenosis is believed to be rare, except as part of Fallot's tetralogy. Single cases have been described by Lafitte (1892), by Lev and Strauss (1942), and by Dow et al. (1950). Three of the eight described here have already been reported briefly by Wood (1950). The diagnosis in six of these cases rests on the findings at cardiac catheterization, and has been confirmed subsequently in one at operation and in one at necropsy. Two others are included solely on clinical grounds.

Symptomatically and functionally, infundibular stenosis does not differ from valvular stenosis. Three of our cases were mild, three moderate, and two severe. The chief difference in the physical signs between the two types of stenosis lay in the site of the thrill and murmur. In infundibular stenosis these were located lower than in valvular stenosis and over a wider area. Thus the thrill was easily felt as low as the fourth space in seven of the cases, though it was usually maximal in the third space, and also appreciable in the second space. The thrill was localized in the second space in only one instance, and in the fourth space in only one. When the stenosis was exceptionally low, the left parasternal lift over the right ventricle did not occur, even in our most severe case (proved at operation).

The cardiograms in these eight cases correlated with the rest of the findings, and showed the same variation from normality to gross right ventricular preponderance that was described in the valvular group.

A consistent difference between valvular and infundibular stenosis was seen radiologically, for the characteristic post-stenotic dilatation of the pulmonary artery which was so constant in valvular stenosis was not observed (Fig. 10). In one case a separate infundibular chamber was outlined by means of angiocardiography and the diagnosis was proved subsequently at operation.

Cardiac catheterization revealed three different pressure zones, the diastolic pressure in the infundibular chamber being lower than that in the pulmonary artery, and the systolic pressure in the infundibular chamber being far lower than that in the body of the right ventricle. When mean pressures were recorded the lowest was in the infundibular chamber. In one case the pressure in the infundibulum was intermediary $(15 \mathrm{~mm}$.) between the low pulmonary artery pressure $(7 \mathrm{~mm}$.), and the raised right ventricular pressure $(21 \mathrm{~mm}$.) $\mathrm{Hg}$.: this case is believed to have both valvular and infundibular stenosis. Pressure changes from one zone to another were nearly always abrupt, and it was usually easy to tell fluoroscopically where the tip of the catheter lay. The abrupt change from infundibular to right ventricular pressure was always much below valve level, in one case so low that only two right ventricular beats were recorded before the tip of the catheter flicked out into the right atrium. For this reason the catheter should be withdrawn particularly slowly in suspected infundibular stenosis, or a tracing from the body of the right ventricle may not be recorded at all.

The actual pressures in the six cases catheterized fitted into the same three groups described for valve stenosis, and harmonized with the clinical assessment of severity.

Summary of the Special Features of Infundibular Stenosis. The general pattern is similar to valve stenosis except in four important respects: (1) the thrill is consistently lower; (2) the pulmonary artery is not dilated; (3) there may be no right ventricular parasternal lift if the stenosis is exceptionally low; and (4) cardiac catheterization may reveal three different pressure zones, the lowest in the infundibulum, and proper right ventricular pulsation does not appear until the catheter tip is well below valve level. 
FIG. 10.- Simple infundibular stenosis showing no dilatation of the pulmonary artery.

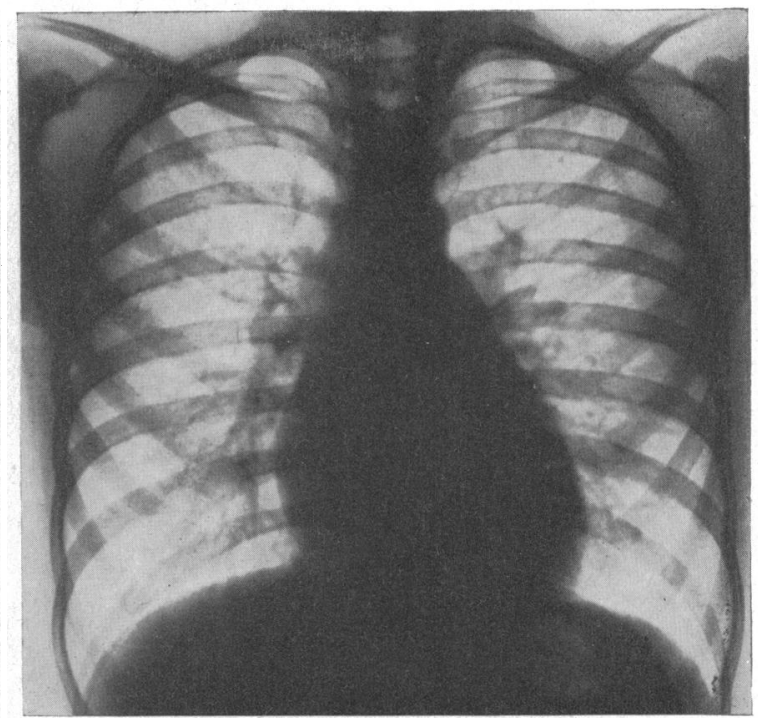

Fig. 11.-Pulmonary stenosis and ventricular septal defect with direct left to right shunt.

\section{Pulmonary Stenosis with Arteriovenous Shunt (Group 2)}

The stenosis may be valvular or infundibular, and the left to right shunt may be aorto-pulmonary through a patent ductus, interventricular through a ventricular septal defect, or interatrial. No case of patent ductus and pulmonary stenosis (Type 2A) has been encountered in this series; it appears to be a very rare combination and will not be further discussed.

\section{Pulmonary Stenosis with Ventricular Septal Defect (Type 2B.)}

There were eight cases in which pulmonary stenosis was found in combination with a V.S.D., through which blood was shunting in the usual direction from left to right ventricle. In four the stenosis was of moderate severity and dominated the clinical picture; in four it was mild, and the features of V.S.D. were more in evidence. The stenosis was valvular in six of the cases, infundibular in one, and both valvular and infundibular in one.

Clinical Features. On examination the first point of interest was the cardiac impulse, for this was either tapping as in simple pulmonary stenosis, or hyperdynamic and left ventricular in quality as in V.S.D. Pulmonary artery pulsation could not be felt in a single instance. The position of the maximum thrill and murmur was low in all cases, and tended to be widespread as in infundibular stenosis. The second heart sound varied greatly. In four it was single, in two rather closely split, in one (with right branch block) widely split, and in one it was too obscured by the murmur to analyse.

The electrocardiogram was normal in one case, showed left ventricular preponderance in two, right ventricular dominance of mild grade in three, and right bundle branch block in two. The $\mathbf{P}$ wave was normal in all.

$\mathrm{X}$-rays showed dilatation of the pulmonary artery, except in the two with infundibular stenosis and in one other. Slight pulmonary plethora was seen in five, but the peripheral vascular markings in the lungs looked normal in the other three (Fig. 11).

It will be appreciated that there are a sufficient number of variables in the physical signs, cardiogram, and $\mathrm{X}$-ray to make it probable that in any given case a pattern will emerge that tends to be incompatible with either infundibular stenosis or V.S.D. alone. Simple pulmonary valve stenosis is virtually excluded by the low and widespread thrill. 
Physiological Studies. Catheterization demonstrated the presence of a left-to-right interventricular shunt of mild degree, and a pressure in the pulmonary artery significantly lower than that in the right ventricle (Table VII). In one instance the stenosis was infundibular in type, with a large separate chamber (Case 5). In another (Case 7) both valvular and infundibular stenosis appeared to co-exist. The arterial oxygen saturation was not measured in most of the cases, because they were obviously acyanotic, 95 per cent saturation being assumed. But doubt was raised in two instances, and in these it was 94 and 93 per cent (Cases 1 and 6).

TABLE VII

Physiological Studies in Pulmonary Stenosis plus Ventricular Septal Defect

\begin{tabular}{|c|c|c|c|c|c|c|c|}
\hline \multirow{2}{*}{ Case } & \multirow{2}{*}{$\begin{array}{l}\text { Age } \\
\text { in years }\end{array}$} & \multicolumn{3}{|c|}{ Mean pressure, mm. $\mathrm{Hg}$. } & \multicolumn{2}{|c|}{ Oxygen saturation per cent } & \multirow{2}{*}{$\begin{array}{c}\text { Ratio of pulmonary } \\
\text { to systemic blood } \\
\text { flow }\end{array}$} \\
\hline & & R.A. & R.V. & P.A. & $\begin{array}{l}\text { S.V.C. } \\
\text { R.A. }\end{array}$ & $\begin{array}{l}\text { R.V. } \\
\text { P.A. }\end{array}$ & \\
\hline 1 & 8 & 0 & 40 & 17. & 73 & 85 & $2: 1$ \\
\hline 2 & 13 & -2 & 16 & 9 & 66 & 85 & $2: 1$ \\
\hline 3 & 8 & -3 & 37 & 5 & 57 & 65 & $4: 3$ \\
\hline 4 & 7 & 2 & 40 & 32 & 64 & 71 & $4: 3$ \\
\hline 5 & 20 & -1 & $\begin{array}{cc}\text { body } & \text { inf. } \\
19 & 5\end{array}$ & 9 & 74 & 80 & $4: 3$ \\
\hline 6 & 12 & 0 & 22 & 13 & 60 & 76 & $2: 1$ \\
\hline 7 & 6 & -3 & $\begin{array}{cl}\text { body } & \text { inf. } \\
40 & 16\end{array}$ & 5 & 68 & 76 & $4: 3$ \\
\hline 8 & 8 & 2 & 30 & 11 & 71 & 82 & $2: 1$ \\
\hline
\end{tabular}

Pulmonary Stenosis with Reversed Interventricular Shunt (Type 3A)

There can be little doubt that with severe pulmonary stenosis with normal aortic root and V.S.D., a reversed interventricular shunt may occur. The situation is then clinically and functionally indistinguishable from Fallot's tetralogy.

Only one such case has been included in the present series because the diagnosis is difficult to establish without necropsy proof. The diagnosis was made in life in another patient with infundibular stenosis who had an arterial oxygen saturation of 91 per cent and an apparent left to right interventricular shunt when first investigated, and later became intensely cyanosed; but necropsy revealed typical Fallot's tetralogy.

The only case we feel at all sure of was that of a girl of 11 with Grade 2 effort dyspnœa. She had never been blue, even on effort, and her arterial oxygen saturation was normally 97 per cent. She had a small peripheral pulse, a blood pressure of 100/75, normal jugular venous pressure and pulse, tapping apex beat, parasternal lift, absent pulmonary artery pulse, widespread systolic thrill and murmur maximal in the third intercostal space, a single second heart sound, a pointed $P$ wave $2 \mathrm{~mm}$. high, grade 3 right ventricular preponderance, no dilatation of the pulmonary artery, and normal pulmonary vascular markings. A confident diagnosis of simple infundibular stenosis was made.

On cardiac catheterization both the aorta (Fig. 12) and the pulmonary artery were entered from the right ventricle. The pulmonary artery pressure was low $(5 \mathrm{~mm}$.); the aortic pressure was $70 / 48$, the right ventricular pressure below the infundibulum 70/0, and the right atrial pressure $6 /-2 \mathrm{~mm}$. (Fig. 13). Atrial systole generated a pressure of $6 \mathrm{~mm}$. Samples in close temporal relationship from the aorta and right subclavian artery were 65 and 72 per cent saturated with oxygen, and from the right ventricle 55 per cent. Earlier samples from the pulmonary artery, right atrium and S.V.C. were 72, 72, and 64 per cent saturated respectively. Temporary reversal of the shunt was attributed to a transient fall of systemic blood pressure, the child complaining of a little light-headedness at the time.

\section{Pulmonary Stenosis with Atrial Septal Defect (Type 2C)}

In A.S.D. the direction of the blood flow between the two atria is determined by the pressure relationship between them. In an uncomplicated case, since the pressure in the left atrium is higher 


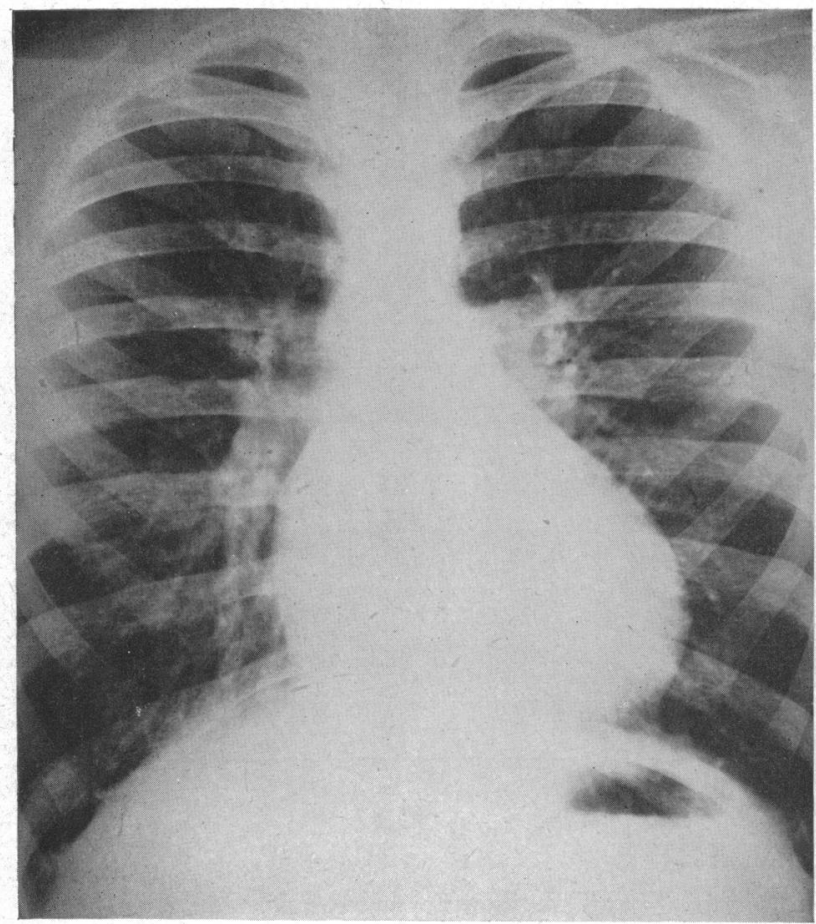

A

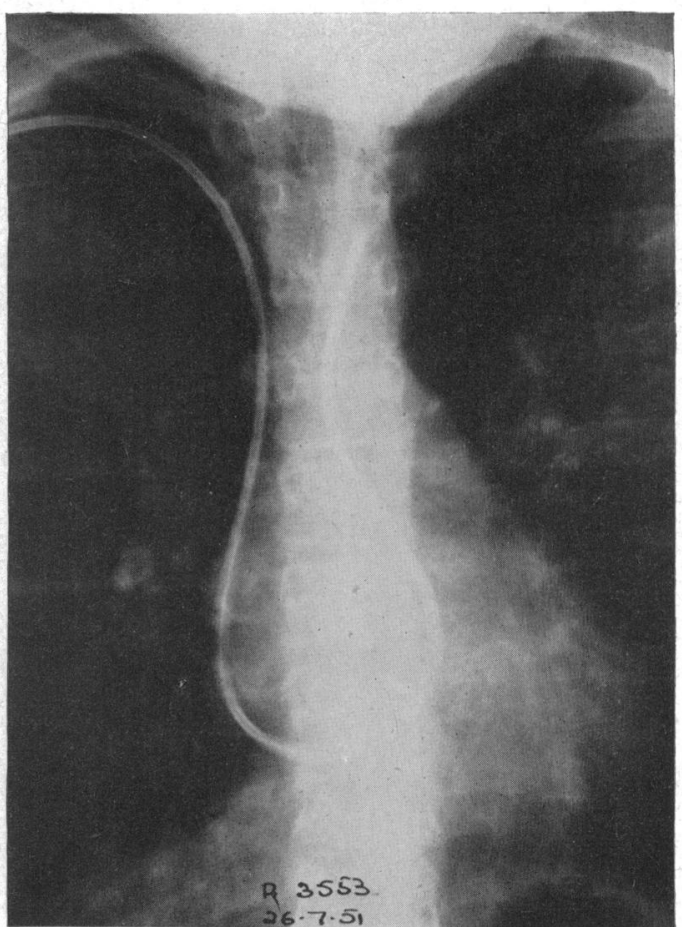

B

Fig. 12.-Pulmonary stenosis with normal aortic root and with ventricular septal defect and transient reversal of shunt: (A) Teleradiogram; (B) The catheter has entered the aorta through a ventricular septal defect.

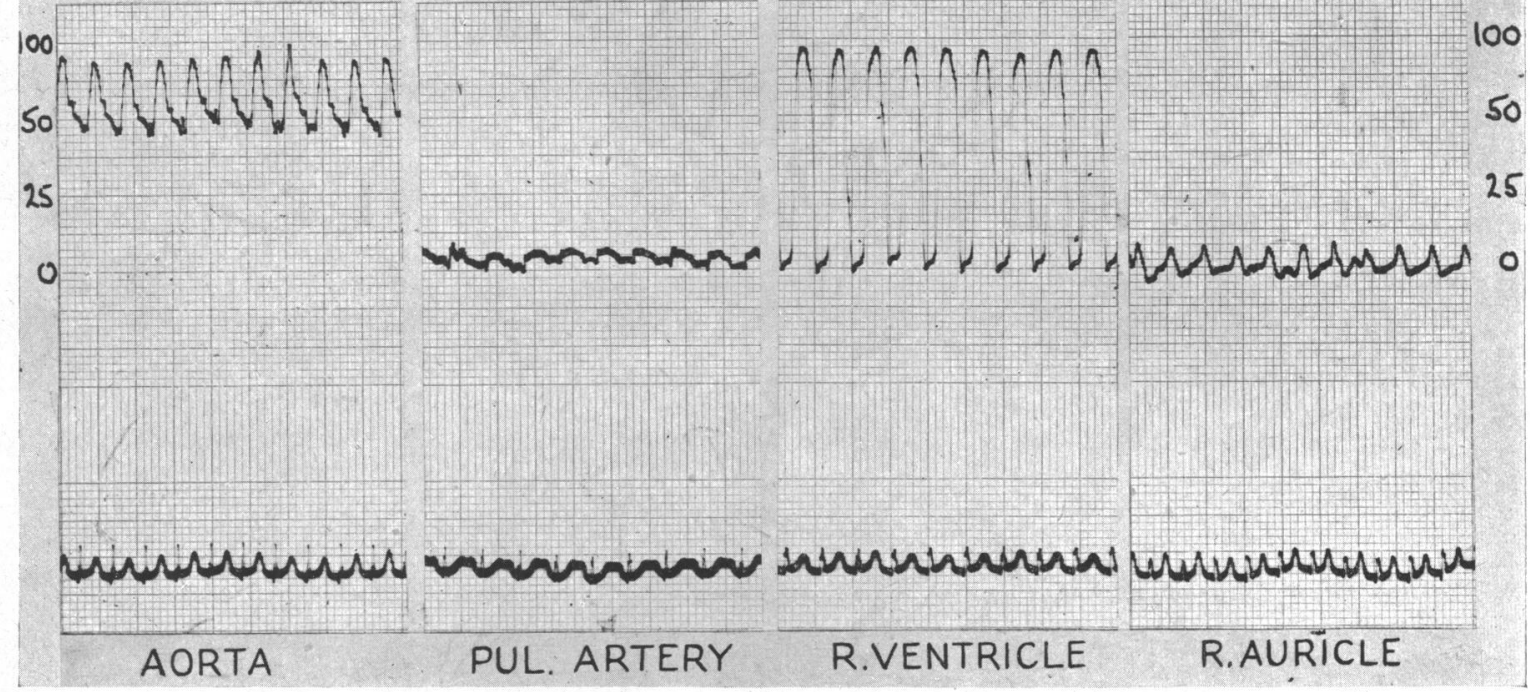

Fig. 13. - Pressure tracings obtained from the aorta, pulmonary artery, right ventricle, and right atrium in a case of pulmonary stenosis with normal aortic root and reversed interventricular shunt. The aortic and right ventricular systolic pressures are identical. Case shown in Fig. 12. The upper 100 on each side in the Figure should be 75. 
than that in the right, the shunt is from left to right. Pulmonary stenosis, however, may raise the pressure in the right atrium and lower it in the left, and under these circumstances the shunt may be reversed. To effect these necessary pressure changes the stenosis must be severe. But in mild or moderate cases of pulmonary stenosis the shunt is in the ordinary direction, from left to right. There were seven such cases in the present series, five of which were proved by means of cardiac catheterization. Pulmonary stenosis was mild or relatively mild in all seven, was valvular in type, and was not suspected clinically in two of the patients. The clinical features were determined largely by the more significant lesion: this was A.S.D. in four, and pulmonary stenosis in three cases. The importance of the combination lies in the potential reversibility of the shunt, and in the hazard of bacterial endocarditis which would not be expected in uncomplicated A.S.D.

The most important physical sign of pulmonary stenosis, which occurred in all seven cases, was an impressive systolic thrill over the pulmonary area. In a comparable series of 40 cases of proved uncomplicated A.S.D., a pulmonary systolic thrill was felt in ten $(25 \%)$. The presence of a thrill is therefore suggestive, but not conclusive. It favours pulmonary stenosis as right bundle branch block favours A.S.D. A second point is the behaviour of the second heart sound. This was widely split (grade 3 ) in only one of the seven cases: in three it appeared normally split (grade 2), in two rather closely split, and in one it was single. In two of those with split second sounds, the pulmonary element was distincly soft.

The electrocardiogram was usually consistent with uncomplicated A.S.D., but the presence of a fairly well developed $P$ pulmonale in one instance, and of exceptionally tall secondary $R$ waves in lead V1 in two cases, suggested associated pulmonary hypertension or stenosis, and the second heart sound excluded hypertension.

The X-ray appearances were consistent with uncomplicated A.S.D. in all seven cases (Fig. 14). The presence of pulmonary plethora was helpful in the three with an absent or diminished pulmonary element of the second heart sound, because associated A.S.D. could not otherwise have been diagnosed at the bedside.

The results of cardiac catheterization are given in detail in Table VIII. The slightly reduced oxygen saturation in some of the left atrial and brachial artery samples does not mean temporary

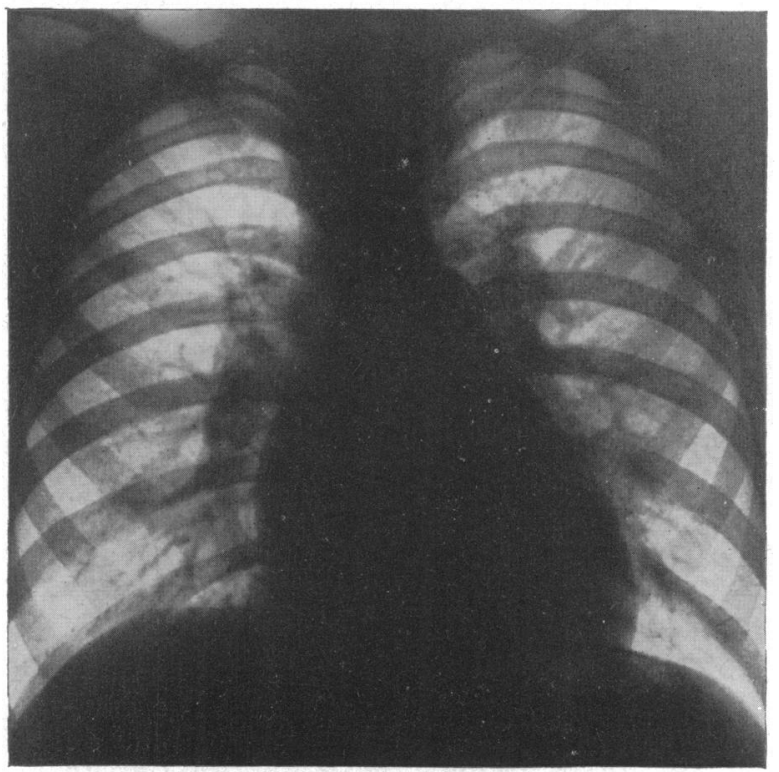

FIG. 14.-Pulmonary stenosis and atrial septal defect with direct left to right shunt. 
TABLE VIII

Physiological Studies of five Cases of Pulmonary Stenosis plus Atrial Septal Defect

\begin{tabular}{|c|c|c|c|c|c|c|c|c|c|c|c|c|c|}
\hline \multirow{3}{*}{ Case } & \multirow{3}{*}{$\begin{array}{c}\text { Age } \\
\text { in } \\
\text { years }\end{array}$} & \multirow{2}{*}{\multicolumn{3}{|c|}{$\begin{array}{l}\text { Mean Pressures, } \\
\mathrm{mm} . \mathrm{Hg}\end{array}$}} & \multirow{2}{*}{\multicolumn{5}{|c|}{ Oxygen Saturation per cent }} & \multirow{3}{*}{$\underset{\text { capacity }}{\mathrm{O}_{2}}$} & \multirow{3}{*}{$\begin{array}{c}\underset{\mathrm{O}_{2}}{\text { consump- }} \\
\text { tion } \\
\mathrm{ml} / \mathrm{min} .\end{array}$} & \multicolumn{2}{|c|}{$\mathrm{L} / \mathrm{min}$. } \\
\hline & & & & & & & & & & & & Sys. & Pul \\
\hline & & R.A. & R.V. & P.A. & S.V.C. & $\begin{array}{l}\text { R.A. R.V. } \\
\text { P.A. }\end{array}$ & $\begin{array}{l}\text { Pul. } \\
\text { Vein }\end{array}$ & L.A. & $\begin{array}{c}\text { Brach. } \\
\text { art. }\end{array} \mid$ & & & $\begin{array}{l}\text { blood } \\
\text { flow }\end{array}$ & $\begin{array}{l}\text { blood } \\
\text { flow }\end{array}$ \\
\hline 1 & 10 & -1 & 23 & 7 & 56 & $72-74$ & - & 93 & 89 & 180 & 236 & $3 \cdot 6$ & 7 \\
\hline 2 & 13 & 0 & 18 & 16 & 76 & $83-87$ & - & 92 & 93 & 190 & 245 & 7 & $17 \cdot 5$ \\
\hline 3 & 20 & 2 & 25 & 15 & 59 & $86-88$ & - & 95 & 94 & 172 & 250 & 4 & $15 \cdot 6$ \\
\hline 4 & 18 & 0 & 15 & 5 & 50 & $64-66$ & - & - & 89 & 175 & 212 & 3 & 4 \\
\hline 5 & 8 & 3 & 15 & 8 & 64 & $80-85$ & 91 & 92 & 96 & 186 & 166 & 3 & 6 \\
\hline
\end{tabular}

reversal of the shunt, because parallel observations on pulmonary venous samples in many uncomplicated cases of A.S.D. investigated at the Institute of Cardiology have shown comparable reduction. The phenomenon may be attributed to slight pulmonary difficulty in fully oxygenating the spate of blood hurrying through a widely dilated pulmonary vascular bed.

\section{Pulmonary Stenosis with Reversed Interatrial Shunt (Type 3 B)}

When there is a right-to-left interatrial shunt in cases of pulmonary stenosis it is usually impossible to tell whether this occurs through an atrial septal defect or a patent foramen ovale. The only way such a distinction could be made in life would be if previous catheterization had demonstrated a left-to-right interatrial shunt or the presence of a functionless patent foramen ovale.

The foramen ovale is usually completely closed by the end of the first year of life, but sometimes not till much later. According to Patten (1931) about 25 per cent of normal adult hearts show probe patency of the foramen ovale, and this incidence decreases with age; in the first two decades of life, the foramen ovale remained pervious in about 35 per cent, while this figure was reduced to about 22 per cent over the age of forty. Patten emphasized that simple probe patency should be distinguished from those abnormal conditions in which the foramen ovale remains inadequately guarded, this occurring in about 1 per cent of subjects that are otherwise normal.

With mild pulmonary stenosis, there is no derangement of the usual pressure relationship between the two atria. The left atrial pressure is higher than the right, and a probe patent foramen ovale remains functionally closed. Three examples were discovered in this series, the catheter passing through the foramen ovale into the left side of the heart. Blood samples from the left atrium and from the brachial artery were normally saturated with oxygen. The future history of these three patients will be interesting, because the stenosis is severe in two of them, and moderate in the third, and a reversed interatrial shunt may well develop in due course. Probe patency of the foramen ovale was also discovered in three patients with Fallot's tetralogy: samples from the left atrium were obtained in two of these and proved to be 90 and 95 per cent saturated with oxygen; in the third the sample was probably inadvertently taken from the left ventricle because it was the same as the sample taken deliberately from that chamber ( $84 \%$ saturated).

It is clear that pulmonary stenosis must be truly severe to cause a reversed interatrial shunt in patients who happen to have a patent foramen ovale. It is also clear that patients with Fallot's tetralogy and probe patent foramen ovale are unlikely to develop.a reversed interatrial shunt, because the pressure in the right side of the heart, at rest or on effort, does not rise high enough. It has already been demonstrated that patients with relatively mild pulmonary stenosis and A.S.D. have a direct left-to-right interatrial shunt. Pulmonary stenosis with reversed interatrial shunt is therefore always severe, whether the shunt is through a patent foramen ovale or through an A.S.D.

There were eight patients with this diagnosis in the present series, seven proved by cardiac catheterization, five by angiocardiography, and four by necropsy. Only one has been included 
entirely on clinical grounds, and is still awaiting confirmation. Five of these have already been described briefly by Wood (1950) and one of them also by Allanby and Campbell (1949). Five were female and three male. Their ages were $9,21,6,22,11,26,15$, and 11 years.

\section{Clinical Features}

As explained above these cases were all severe, and cyanosed more or less by definition. According to Bedford and Brown (1937), cyanosis and clubbing usually appear late, in the second or third decades, and Allanby and Campbell (1949) believe this " late onset of increasing cyanosis and disability" to be the most characteristic clinical feature of the anomaly. Such behaviour is determined by late reversal of an interatrial shunt in cases with A.S.D., by the late development of a reversed intefatrial shunt in cases with probe patent foramen ovale, or by increasing right to left interatrial shunt as age advances. The factors responsible for shunt reversal or for increasing right to left shunt, have recently been discussed by Allanby and Campbell (1949) and include infection and thrombosis of the pulmonary valve and inability of the stenosed valve to grow in size at the same rate as the heart. The essential physiological change is a rising right atrial pressure. In the eight cases reported here cyanosis dated from birth or infancy in six, but became worse at puberty in three of these; clubbing was associated in each of these six cases, but was slight in two. Central cyanosis was only just detectable in the other two patients, and neither had clubbed fingers.

All eight patients were breathless on effort, four being more or less incapacitated. Pain, with some of the features of angina pectoris, occurred in one, and syncopal attacks in another. Only one patient was said to have squatted in childhood.

The clinical findings were characteristic. In addition to the cyanosis and clubbing described above, all had polycythæmia, the lowest hæmoglobin level being 120 per cent. All seven proved cases had the classical signs of severe pulmonary valve stenosis with normal aortic root; thus the peripheral pulse was small in all but one; typical giant $a$ waves were seen in the neck in every instance; the cardiac impulse was tapping in all but one, in which a strong right ventricular heave extended from the sternal border to the apex beat; a powerful parasternal lift was felt in all cases, but no pulsation could be felt over the pulmonary artery itself; a localized systolic thrill was easily felt in five cases, and was always maximal in the second left intercostal space high up over the pulmonary artery; the two exceptions had a localized systolic murmur; the second heart sound was invariably single. In one case a diastolic murmur was heard in the fourth intercostal space from the sternal border to the apex beat, giving rise to the same cadence heard with mitral diastolic murmurs; this was attributed to turbulence set up at the foramen ovale, for no other cause could be found at necropsy. A similar loud diastolic murmur was heard at the apex beat in an uncomplicated case of A.S.D. in which necropsy showed a normal mitral valve.

The cardiogram showed sharp P waves from 2 to $5 \mathrm{~mm}$. high in all cases, gross right ventricular preponderance (grade 4) in six, slight right ventricular preponderance in one, and right branch block in one.

Radiologically the right heart was enlarged in all but one, and the pulmonary artery was dilated in five (Fig. 15). One of those without post-stenotic dilatation had a valvular stenosis at necropsy; the other exception amongst the proved cases appeared to have a separate infundibular chamber according to the angiocardiogram, but this was not demonstrated on cardiac catheterization. All cases showed evidence of pulmonary ischæmia.

\section{Physiological Studies}

Catheterization of these patients revealed several important features (Table IX). (1) The right atrial systolic pressure was always raised when measured by means of an electrical manometer. The amplitude of the giant $a$ wave was commonly around $10 \mathrm{~mm}$. $\mathrm{Hg}$, as in the acyanotic cases of severe pulmonary stenosis. (2) When the left atrium was entered, the pressure in that chamber was low. This is attributed to the severity of the stenosis, the low pulmonary artery pressure being unable to maintain a proper pulmonary venous pressure. Thus severe pulmonary stenosis not only raises the right atrial pressure, but lowers the left, and so provides a second cause for shunt reversal. (3) The right ventricular pressure was greatly elevated (mean 44 to $95 \mathrm{~mm}$.), the systolic 


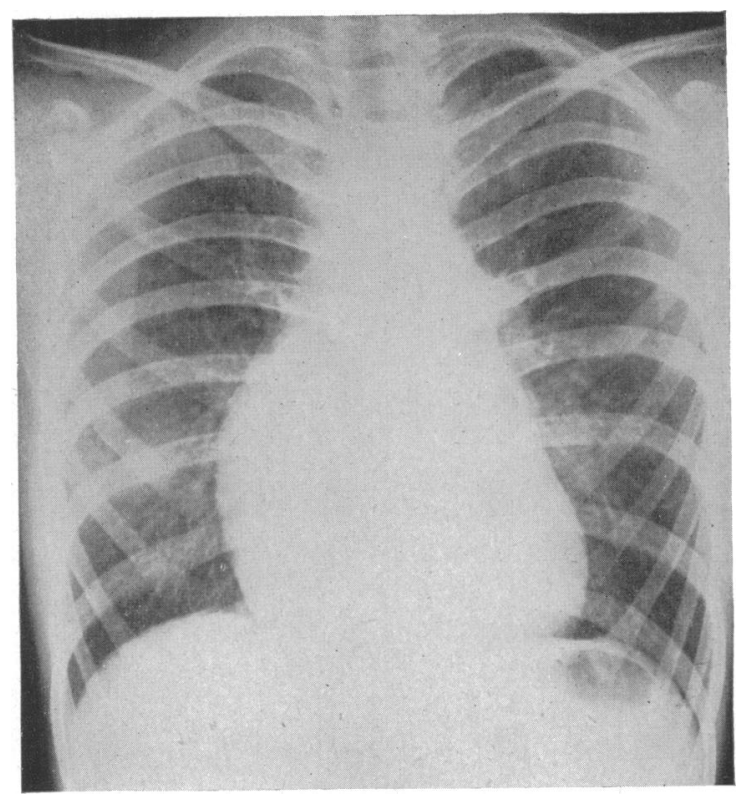

Fig. 15.-Pulmonary stenosis with reversed interatrial shunt showing pulmonary ischæmia, dilatation of the pulmonary artery, and enlargement of the right atrium and ventricle.

TABLE IX

Physiological Studies in Pulmonary Stenosis with Reversed Interatrial Shunt

\begin{tabular}{|c|c|c|c|c|c|c|c|c|c|c|c|c|c|}
\hline \multirow{2}{*}{ Case } & \multirow{2}{*}{$\begin{array}{c}\text { Age } \\
\text { in } \\
\text { years }\end{array}$} & \multicolumn{4}{|c|}{ Pressure (mm. Hg) } & \multicolumn{3}{|c|}{ Oxygen Sat. (per cent) } & \multirow{2}{*}{$\begin{array}{c}\text { Oxygen } \\
\text { capacity } \\
\mathrm{ml} / \mathrm{L} .\end{array}$} & \multirow{2}{*}{$\begin{array}{c}\text { Oxygen } \\
\text { consump- } \\
\text { tion } \\
\mathrm{ml} / \mathrm{min} .\end{array}$} & \multicolumn{2}{|c|}{$\begin{array}{l}\text { Blood Flow } \\
\text { L/min. }\end{array}$} & \multirow{2}{*}{ Proof } \\
\hline & & L.A. & R.A. & R.V. & P.A. & $\begin{array}{cc}\text { S.C.V. } & \text { R.A. } \\
\text { R.V. } & \text { P.A. }\end{array}$ & L.A. & Art. & & & Pulm. & Syst. & \\
\hline 1 & 9 & 1 & 3 & 44 & 4 & 50 & 68 & 70 & 240 & - & - & - & $\begin{array}{l}\text { Valvulotomy } \\
\text { (good result) }\end{array}$ \\
\hline 2 & 21 & 4 & 4 & 52 & - & 51 & - & 75 & 240 & - & - & - & $\begin{array}{l}\text { Angio. Valv. } \\
\text { Necropsy }\end{array}$ \\
\hline .3 & 6 & 5 & 15 & - & - & - & 86 & - & 216 & - & - & - & Necropsy \\
\hline 4 & 22 & 3 & 3 & 52 & 4 & $27-36$ & 50 & 51 & 280 & 266 & $1 \cdot 4$ & $4 \cdot 3$ & $\begin{array}{l}\text { Angio. Valv. } \\
\text { Necropsy }\end{array}$ \\
\hline 5 & 11 & -1 & 2 & $?$ & - & $54-59$ & 77 & 84 & 256 & 191 & 2 & 3 & $\begin{array}{l}\text { Angio. Valv. } \\
\text { (good result) }\end{array}$ \\
\hline 6 & 26 & 3 & $10 / 0$ & $\begin{array}{c}105 \\
0\end{array}$ & 10 & $62-66$ & 74 & 71 & 310 & 250 & $2 \cdot 5$ & 7 & Angio. \\
\hline 7 & $0^{15}$ & - & $8 /-6$ & $\begin{array}{l}260 . \\
5 \\
(95)\end{array}$ & 3 & $63-65$ & - & 86 & 240 & 295 & 4 & 6 & $\begin{array}{l}\text { Valvulotomy } \\
\text { Necropsy }\end{array}$ \\
\hline
\end{tabular}


level often being higher than that in the aorta (Fig. 16). This at once distinguishes pulmonary stenosis with reversed interatrial shunt from Fallot's tetralogy. (4) The pulmonary artery pressure was always low (mean 2 to $10 \mathrm{~mm}$.). (5) Samples from the left atrium and left ventricle, when obtained, were similarly unsaturated and approximated closely to arterial samples (average saturation figure about $70 \%$; range 50 to $86 \%$ ). (6) Samples were obtained from the pulmonary veins in two cases, and these were normally saturated $(95 \%)$. (7) The pulmonary blood flow was reduced $(1.4$ to $4 \mathrm{~L} / \mathrm{min}$.) in the four cases in which the oxygen consumption was measured, and the oxygen content of venous samples was, of course, abnormally low, 30 to 65 per cent saturated.

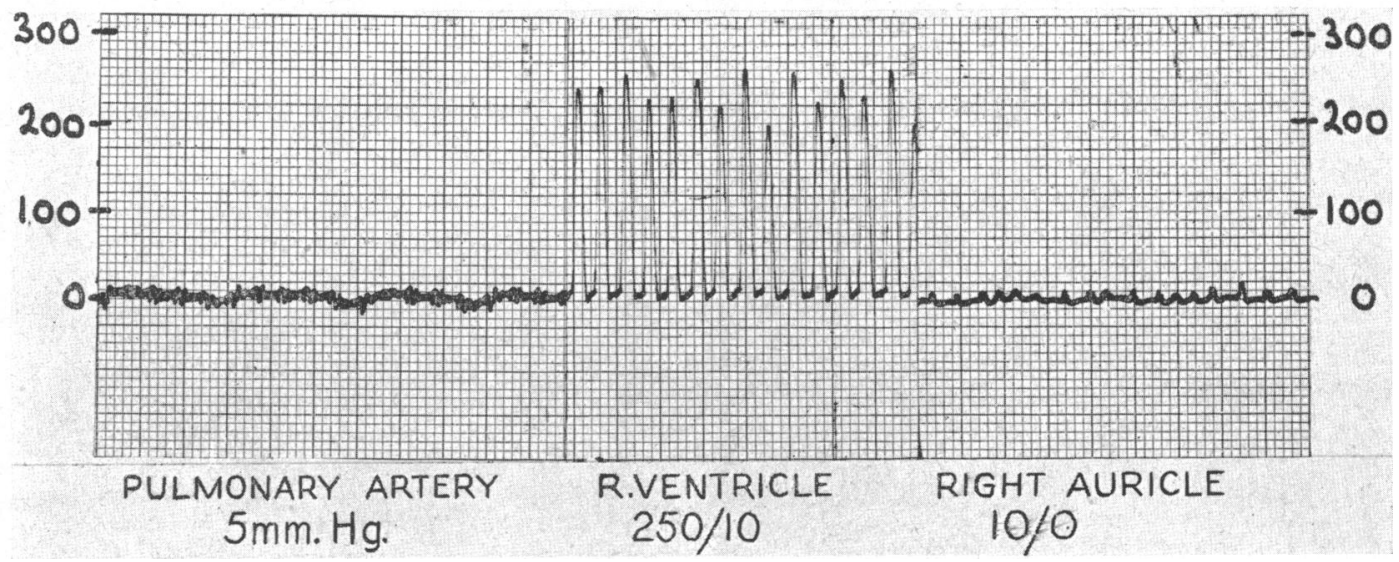

FIG. 16.-Pressure tracings from a case of pulmonary stenosis with reversed interatrial shunt showing a right ventricular systolic pressure well above the systemic blood pressure.

\section{Differential Diagnosis}

Since the Blalock anastomotic operation is not advised for pulmonary stenosis with reversed interatrial shunt, it is imperative to distinguish this condition from the tetralogy of Fallot. As a rule, this presents little difficulty. Historically, the delayed onset of cyanosis and clubbing, or the sudden increase of cyanosis at puberty or later, is very typical and virtually diagnostic of shunt reversal, but it is by no means uncommon for these cases to be cyanosed from birth, and the diagnosis may have to be made long before puberty.

We believe that by far the most important sign distinguishing the two conditions is the presence or absence of a giant $a$ wave in the venous pulse, with or without presystolic hepatic pulsation. We have never yet seen an $a$ wave of such proportions in a proven case of the tetralogy, nor indeed in any condition other than severe pulmonary stenosis with closed ventricular septum, severe pulmonary hypertension with closed ventricular septum and closed ductus, and acquired tricuspid stenosis (not congenital atresia).

In the tetralogy of Fallot, the V.S.D. acts as a safety valve and the right ventricular systolic pressure can never exceed that in the left ventricle and aorta. The right ventricle does not therefore require the kind of atrial help it needs in order to'generate pressures well above the systemic level.

Another helpful sign is the moon facies associated with severe pulmonary stenosis with normal aortic root. This does not seem to occur in the tetralogy. The degree of right ventricular lift is usually greater in severe pulmonary stenosis and may be barely perceptible in the tetralogy. Again, a right ventricular heave extending as far to the left as the apex beat must be very rare, if it occurs at all, in the tetralogy.

Finally, the X-ray appearances may be helpful, because though pulmonary ischæmia occurs in both, a dilated pulmonary artery is rare in the tetralogy, even in the 40 per cent with valvular stenosis, and the right side of the heart is usually much larger in pulmonary stenosis with normal aortic root. The electrocardiogram is not helpful, because a well developed P pulmonale and strong right ventricular preponderance are common in Fallot's tetraolgy, although vectorcardiography may well show a different kind of loop.

It is usually possible to prove the diagnosis by means of cardiac catheterization according to the criteria already described. In Fallot's tetralogy the catheter may pass through a probe patent foramen ovale and left atrial samples should then be normally saturated with oxygen; but there are two pitfalls. The tip of 
the catheter may lie in a main pulmonary vein and samples are then normally saturated in both conditions, or it may inadvertently slip through the mitral valve into the left ventricle while the sample is being taken, in which event the sample shows a low saturation value in both conditions. It is not yet known whether the atrial oxygen saturation in Fallot's tetralogy is lower than that in the left ventricle.

Finally, angiocardiography may solve the problem by revealing immediate filling of the left atrium in cases of pulmonary stenosis with reversed interatrial shunt, and early filling of the aorta without opacification of the left atrium in the tetralogy, as described by Campbell and Hills (1950).

\section{Acquired Pulmonary Stenosis (Group C).}

It is not the purpose of this paper to deal with Fallot's tetralogy (group B), but two cases of acquired pulmonary stenosis are included for comparison and for the sake of interest.

Case 1. A man of $\mathbf{4 2}$ developed increasing congestive heart failure of uncertain ætiology with tricuspid incompetence and ascites between July and September, 1950, and failed to respond to bed rest, digitalis, and mercurial diuretics. At a routine examination in 1948, nothing abnormal had been discovered apart from a soft basal systolic murmur. Examination by one of us in October, 1950, showed advanced heart failure, a small peripheral pulse, gross tricuspid incompetence, tapping cardiac impulse, right ventricular parasternal heave, impalpable pulmonary artery pulsation, high pulmonary systolic thrill and murmur, and a single second heart sound. The Wassermann and Kahn reactions were strongly positive. No gumma in the region of the pulmonary artery and no aneurysm of the root of the ascending aorta could be seen radiologically; but the stem of the pulmonary artery was dilated, the right atrium and ventricle were enlarged, and the pulmonary vascular markings were light. A diagnosis of simple pulmonary valve stenosis of severe grade was made and syphilis was believed to be coincidental. Cardiac catheterization confirmed the diagnosis, the mean right ventricular pressure being $45 \mathrm{~mm}$., and the mean pulmonary artery pressure $6 \mathrm{~mm}$. (Fig. 17). The change of pressure occurred abruptly at about valve level. The arterial oxygen

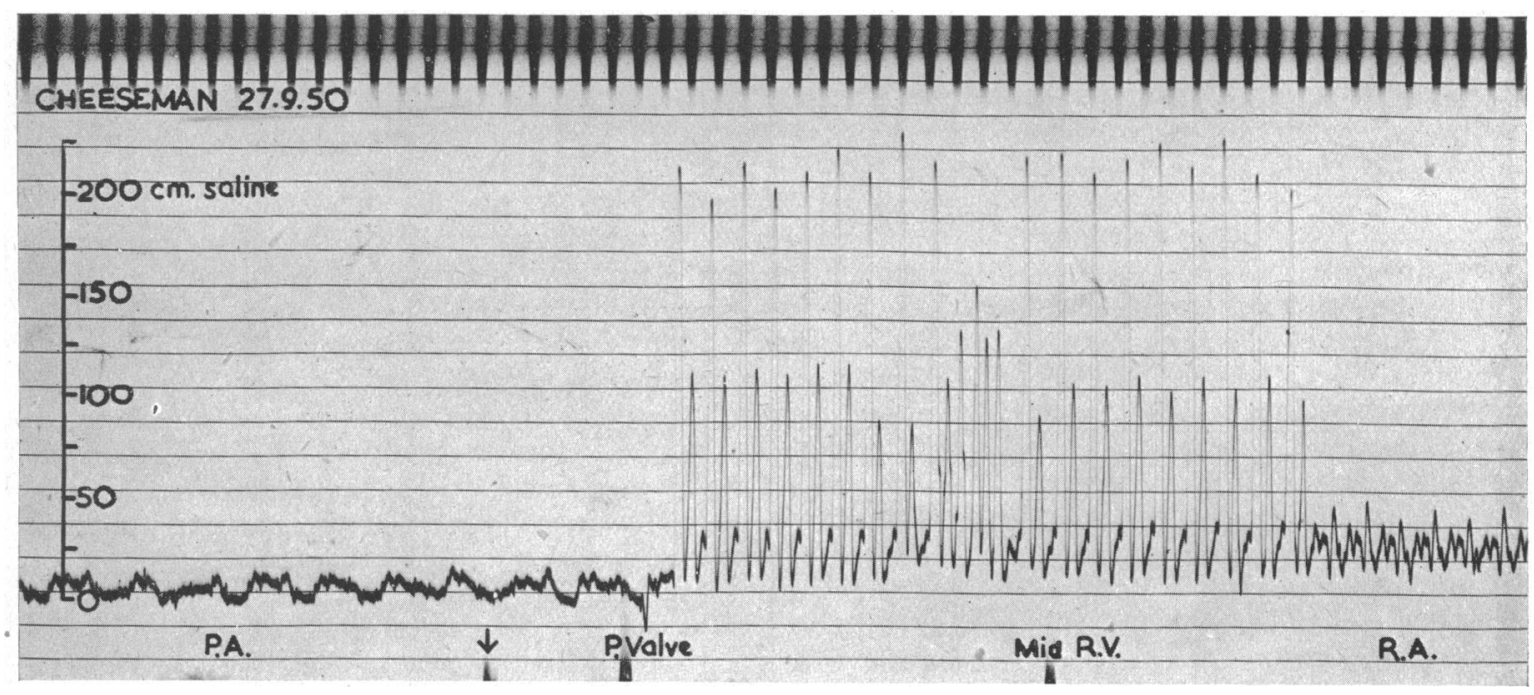

FIG. 17.-Pressure tracing from the pulmonary artery and right ventricle in a case of acquired pulmonary stenosis believed to be syphilitic in origin.

- saturation was 92 per cent, the arterio-venous oxygen difference 110 to $115 \mathrm{ml} / \mathrm{L}$, and the cardiac output 2 litres a minute. With considerable courage Mr. R. C. Brock agreed to perform a pulmonary valvulotomy, after a period of further medical treatment, which included a low sodium diet and penicillin, had abolished the tricuspid incompetence, lowered the venous pressure, and caused disappearance of the odema. At this stage a prominant $a$ wave replaced the systolic venous wave.

At thoracotomy the pericardium was thick and adherent over the base of the right ventricle and pulmonary artery, and the right ventricle was dilated and extremely thin walled. The pulmonary valve was normal, there was no aortic aneurysm, no gumma, and no fibrous ring constricting the base of the pulmonary artery; but there was an unidentified obstruction within the lumen of the pulmonary artery 
about $2 \mathrm{~cm}$. above the valve. Beyond the obstruction the pressure was low; proximal to it the root of the pulmonary artery was tense and bulging. A series of dilators of increasing width up to $1 \mathrm{~cm}$. were passed through the obstruction, and the distal pressure rose. Owing to the extreme fragility of the anterior wall of the right ventricle considerable difficulty was experienced in sewing it up, and hæmorrhage was difficult to control.

The final result was excellent, and the patient is now back in his original job of male nurse, and appears to be free from symptoms. The thrill over the pulmonary artery is still present (July 1951), the second heart sound still single, and the right ventricle still lifts; but the venous pressure is normal and there are no signs of cardiac embarrassment.

Case 2. The patient, a girl of 17 , had a large mediastinal cyst or tumour lying beneath the root of the main pulmonary artery and compressing it against the anterior chest wall. There were no symptoms. The arterial and venous pulses were normal. The cardiac impulse was normal and left ventricular in type. There was no parasternal lift, but unlike all other cases of pulmonary stenosis, there was conspicuous pulsation in the second left intercostal space over the pulmonary artery. There was a high pulmonary systolic thrill and murmur, and the second heart sound was single. The electrocardiogram was normal. $\mathrm{X}$-rays showed a well defined, smooth walled, rounded mass in the region of the pulmonary artery or its left branch. An angiocardiogram showed a normal right ventricle and pulmonary artery, but the latter was poorly filled at its base, as might have resulted from flattening of the vessel. Cardiac catheterization revealed a right ventricular pressure of $70 / 3$, and a pulmonary artery pressure of $18 / 12 \mathrm{~mm}$. The cardiac output was $8 \mathrm{~L} / \mathrm{min}$. at rest. She is now awaiting thoracotomy.

\section{COMPLiCATIONS}

Pulmonary Tuberculosis. Although Rokitansky (1852) wrote that cyanosis offered a complete protection against pulmonary tuberculosis, Paul (1871) held that pulmonary stenosis, with or without normal aortic root, predisposed to this disease. Indeed, Norris (1933) stated that tuberculosis occurred in one-third of all cases of pulmonary stenosis, and Fishberg (1931) gave tuberculosis as the cause of death in nearly all the cases that survived the first decade of life; they produced post-mortem evidence to support theif claims. Pulmonary ischæmia, inequality of the pulmonary and bronchial circulations, disturbances of carbon dioxide balance, and lowered pulmonary resistance from the accumulation of toxic metabolites, were all invoked as causative factors.

These views have recently been attacked. Aubertin (1935) denied that pulmonary stenosis predisposed to tuberculosis; in most of his cases he found an adequate explanation for the infection, in a strong family history or other close contact. He showed further that the disease pursued its usual course in these subjects. Auerbach and Stemmerman (1944) agreed with Aubertin that neither lesion seemed to be affected by the other . Gloyne (1936) and Grenet and François-Joly (1936), also found no evidence that the two diseases were causally related.

In the present series frank tuberculosis occurred in only one case, and in this patient there was a strong family history of the disease. In another instance an unexpected and recent Ghon lesion was found at necropsy. This incidence of about 2 per cent is the same as that in the general population.

Bacterial Endocarditis. Sir James Paget (1844) was the first to point out that a deformed valve was peculiarly susceptible to infection, and the pulmonary valve is no exception. Abbott (1925) found infective endocarditis in 20 of 82 cases of pulmonary stenosis of all types. Gelfman and Levine (1942) put the incidence at 29 per cent of all cases over the age of two years. Tuley and Moore (1917) and Posey (1938) emphasized the exuberance of the vegetations which grew on the pulmonary valve.

Bacterial endocarditis occurred in only two cases in the present series, so that it was no more frequent than tuberculosis. On the other hand, bacterial endocarditis of the pulmonary valve does not occur in 2 per cent of the general population. It is regarded as a potential source of danger, and patients should be protected against intercurrent infections, dental extractions and the like by means of prophylactic penicillin.

The two patients who gave a history of bacterial endocarditis were unusually interesting, for the effect of the illness was comparable to valvulotomy. Both were cases of simple pulmonary valve stenosis of severe grade, and both were virtually incapacitated before the infection. One, at the age of 24, 10 years after the infection, is now leading a normal life, and is only breathless when hurrying: in childhood she was unable to walk more than a few steps and used to squat. The second was a young man of 19 who had had bacterial endocarditis four years previously: he was cured of the infection by means of penicillin, and developed pulmonary incompetence during the illness, but his exercise tolerance has improved considerably, so that he can now run upstairs and swim without distress, whereas previously he could not walk upstairs without having to halt on account of breathlessness. 


\section{Prognosis AND TREatment}

The average age of death in Abbott's series (1931) was 20.6 years and the longest period of survival 57 years. Bauer and Astbury (1944) found the average age of death was $22 \cdot 8$ years, the range being 10 to 45 . It must be clearly understood that the prognosis in mild cases is altogether different from that in severe cases; mild cases may be expected to enjoy middle age, and several have reached the age of 70 (Green et al., 1949). On the other hand, severe cases are likely to die from congestive heart failure in the second or third decade.

Pulmonary valvulotomy was carried out at the Brompton Hospital by Mr. R. C. Brock in 10 of the present series of 71 cases. These comprised four cases of simple valvular stenosis, one of simple infundibular stenosis, four of valve stenosis with reversed interatrial shunt, and one of acquired pulmonary stenosis presumed to be syphilitic in origin. Three died within ten days of the operation-all cases with reversed interatrial shunt. Of the other seven, four have done extremely well, and two promise to do well but have not yet been observed long enough for proper appraisal.

By February 1951, Brock had performed 50 pulmonary valvulotomies, 23 in cases with Fallot's tetralogy, 27 in cases with normal aortic root. In this series there were ten deaths. It will be noticed, however, that Brock reported 10 deaths in his first 33 cases (Brock and Campbell, 1950) so that none of the last seventeen could have died.

The late results of valvulotomy have yet to be witnessed.

\section{SUMMARY}

A series of 71 cases of pulmonary stenosis with normal aortic root is presented. A new classification is offered, based on function as well as structure.

The incidence of the anomaly was 12 per cent of all cases of congenital heart disease. There were 37 cases of simple pulmonary valve stenosis and 8 of simple infundibular stenosis. Their clinical features are described in detail, and it is claimed that an accurate bed-side diagnosis is nearly always possible.

Severe cases are characterized by effort intolerance, peripheral cyanosis, moon facies, small peripheral pulse, giant $a$ waves in the jugular venous pulse, presystolic hepatic pulsation, tapping cardiac impulse, parasternal right ventricular heave, impalpable pulmonary artery, high pulmonary systolic thrill and murmur, and single second heart sound. The electrocardiogram shows the $P$ pulmonale and strong right ventricular dominance. X-rays show pulmonary ischæmia, poststenotic dilatation of the pulmonary artery, and enlargement of the right ventricle and atrium. Catheterization reveals a mean right ventricular pressure of over $40 \mathrm{~mm}$. $\mathrm{Hg}$., and a systolic pressure often well above the systemic pressure. The pulmonary artery pressure is low (2 to $10 \mathrm{~mm}$. Hg.). Atrial systole generates a pressure of around $10 . \mathrm{mm} . \mathrm{Hg}$. The cardiac output is low and relatively fixed.

Infundibular stenosis may be distinguished from valve stenosis by the low position of the thrill, occasionally by the absence of a parasternal lift, by the absence of dilatation of the pulmonary artery, and by means of cardiac catheterization.

Cases of mild valve or infundibular stenosis are symptom free and show little abnormal beyond the systolic thrill and murmur, and post-stenotic dilatation of the pulmonary artery (in the valvular type).

There were 15 cases of pulmonary stenosis with normal aortic root complicated by an arteriovenous intracardiac shunt, 8 through a V.S.D., and 7 through an A.S.D. In about half, the main clinical features were those of pulmonary stenosis; in the other half the signs were determined chiefly by the septal defect.

Pulmonary stenosis with normal aortic root complicated by reversed interventricular shunt was encountered only once. This condition closely resembles Fallot's tetralogy, and may only be distinguished at necropsy. There were 8 examples of pulmonary stenosis with reversed interatrial 
shunt through an A.S.D. or patent foramen ovale. The stenosis was always severe. Such cases may be distinguished from Fallot's tetralogy by the history, by the presence of giant $a$ waves and presystolic hepatic pulsation, by the degree of left parasternal heave, and by the presence of poststenotic dilatation of the pulmonary artery.

Three patients with simple pulmonary valve stenosis had a functionless probe-patent foramen ovale through which a catheter was passed.

Two cases of acquired pulmonary stenosis are described in detail. One was associated with syphilis and one was caused by a mediastinal cyst or tumour.

Bacterial endocarditis improved two severe cases of pulmonary valve stenosis. Clinical pulmonary tuberculosis occurred in only one of the 69 congenital cases; necropsy revealed an unsuspected Ghon focus in a second.

Pulmonary valvulotomy was carried out in ten severe cases. Three died, four are greatly improved, and two recent cases are doing well.

Of the 71 cases comprising this series, 5 were under the care of Dr. Maurice Campbell, 3 under Dr. Evan Bedford, 1 under Dr. William Evans, 2 under Dr. Graham Hayward, and 5 under Dr. Wallace Brigden. We would like to thank these physicians for their kindness in allowing us to investigate their cases and to include them in the series.

We should also like to thank the registrars for helping with the cardiac catheterizations, and Mr. Latham and Mr. Norman for their technical assistance.

\section{REFERENCES}

Abbott, M. E. (1925). Ann. clin. Med., 4, 189.

- (1927). In Osler \& Macrae's Modern Medicine, 3rd ed., Vol. IV, p. 729. Henry Kimpton, London.

- (1936). Atlas of Congenital Heart Disease. New York.

Adams, F. H., Veasy, L. G., Jorgens, J., Siehl, R., Labree, J. W., Shapiro, M. J., and Dwan, P. F. (1951). J. Ped., $38,431$.

Allanby, K. D., and Campbell, M. (1949). Guy's Hosp. Rep., 98, 18.

Ash, R., Wolman, I. J., and Bromer, R. S. (1939). Amer. J. Dis. Child., 58, 8.

Aubertin, Ch. (1935). Paris méd., 1, 413.

Auerbach, S. H. and Harper, H. T. (1947). Amer. Heart J., 34, 131.

Auerbach, O., and Stemmerman, M. G., (1944). Amer. J. med. Sci., 207, 219.

Bauer, D. de F., and Astbury, E. C. (1944). Amer. Heart J., 27, 688.

Barber, J. M., Magidson, O., and Wood, P. (1950). Brit. Heart J., 12, 277.

Bedford, D. E., and Brown, J. W. (1937). In British Encyclopadia of Medicine. Vol. VI, p. 277, London.

Blackford, L. M., and Parker, F. P. (1941). Arch. intern. Med., 67, 1107.

Brock, R. C. (1951). Personal communication.

- and Campbell, M. (1950). Brit. Heart J., 12, 377.

Brown, J. W. (1950). Congenital Heart Disease. 2nd ed., Staples, London.

Campbell, M. (1949). Quart. J. Med. 18, 379.

$\longrightarrow$, and Hills, T. H. (1950). Brit. Heart J., 12, 65.

—, and Reynolds, G. (1949). Arch. Dis. Childh., 24, 294.

Cavina, G. (1915). Arch. Sci. med., 39, 112 and 251.

Clawson, B. J. (1944). Lancet, 64, 135 .

Conte, W. R., McCammon, C. S., and Christie, A. (1945). Amer. J. Dis. Child., 70, 301.

Cossio, P. Quoted by Laubry, C. (1943). Arch. Mal. Caur, 36, 61.

Currens, J. H., Kinney, T. D., and White, P. D. (1945). Amer. Heart J., 30, 491.

Dolgopol, V. (1936). J. Tech. Methods, 16, 96.

Dow, J. W., Levine, H. D., Elkin, M., Haynes, F. W., Hellems, H. K., Whittenberger, J. W., Ferris, B. G., Goodale, W. T., Harvey, W. P., Eppinger, E. C., and Dexter, L. (1950). Circulation, 1, 267.

*Fallot, A. (1888). Marseille Med., 25, 77, 138, 207, 270, 341, 403.

Farre, J. R. (1814). On Malformations of the Heart. London.

Fishberg, M. (1931). Pulmonary Tuberculosis. 4th ed., Vol. II, p. 197. London.

Freed, A. N., and Budnitz, J. (1946). Amer. Heart J., 31, 369.

Gee, S. (1893). Auscultation and Percussion. 4th ed., p. 152, London.

Gelfman, R., and Levine, S. A. (1942). Amer. J. med. Sci., 204, 324.

Gibson, S., and Clifton, W. M. (1938). Amer. J. Dis. Child., 55, 761.

Gintrac, E. (1824). Observations et Recherches sur la Cyanose ou Maladie Bleu. Paris.

Gloyne, S. R. (1936). Tubercle, 17, 455.

Gøtzsche, H., Eskildsen, P., and Hansen, A. T. (1951). Acta med. scand., 139, 431.

Greene, D. G., Baldwin, E. de F., Baldwin, J. S., Himmelstein, A., Roh, C. E., and Cournand, A. (1949). Amer. J. Med., 6, 24.

Gregg, N. McA. (1941). Trans. Ophth. Soc. Aust., 3, 35.

* We have been unable to obtain this journal in this country so have not read Fallot's werk in the original. 
Grenet, H., and François-Joly, J. (1936). Arck. méd. Enf., 39, 789.

Grönwall, H., and Selander, P. (1948). Nord, med., 37, 409.

Gross, P. (1941). Arch. Path., 31, 163.

Humphrey, L. (1909). In Allbutt and Rolleston's System of Medicine, Vol. VI, p. 307. London.

Hyman, A. L., Levy, L., Bagnetto, R., Ordway, N. K., and Hull, E., (1951). Ann. intern. Med., $34,90$.

Ingham, D. W. (1938). J. Tech. Methods, 18, 131.

Jacobius, H. L., and Moore, R. A. (1938). J. Tech. Methods, 18, 133.

Joly, F., Carlotti, J., Sicot, J-R., and Piton, A. (1950). Arch. Mal. Cour, 43, 687.

Keith, A. (1909). Lancet, $2,359$.

Lafitte, A. (1892). Bull. Socl Anat., Paris, 67, 13.

Laubry, Ch., and Pezzi, C. (1913). Arch. Mal Cour., 6, 433.

—_, (1921). Traité des Maladies Congénitales du Caur, p. 99 et seq. Paris.

Leatham, A. (1951). Brit. Heart J., 13, 153.

Leech, F. B. (1935). J. Ped., 7, 802.

Lev, M., and Strauss, S. (1942). Arch. intern. Med., 70, 52.

Love, W. S. (1937). Med. Clin. N. Amer., 21, 1291.

Mackenzie, J. (1902). The Study of the Pulse. Young J. Pentland, Edinburgh.

Mannheimer, E. (1949). Arch. Dis. Childh., 24, 264.

Maraist, F., Daley, R., Draper, A., Heimbecker, R., Damman, F., Kieffer, R., King, J. T., Ferencz, C., and Bing, R. J., Bull. Johns Hopk. Hosp., 88, 1.

McGinn, S. (1936). J. Tech. Methods, 16, 98.

Miller, H. C. (1948). Mod. Concepts. C'ardiovasc. Disease, 17, 27.

Morgagni, J. B. (1761). De Sedibus et Causis Morborum. Epist. 17, p. 435. Translation by Benjamin Alexander, 1769.

Nicholson, M. M. (1936). J. Tech. Methods, 15, 100.

Norris, G. W. (1904). Amer. J. med. Sci., 128, 649.

Norris, A. W. (1933). In Norris and Landis' Diseases of the Chest, 5th ed., p. 880 . London.

Paget, J. (1844). Med.-chir. trans., 27, 162.

Patten, B. M. (1931). Amer. J. Anat., 48, 19.

Paul, C. (1871). Bull Soc. méd. Hôp. Paris, 8, 45.

Peacock, T. B. (1858). On Malformations, etc. of the Human Heart. Churchill, London.

Pollack, A. A., Taylor, B. E., Odel, H. M., and Burchell, H. B. (1948). Proc. Mayo Clin., $23,516$.

Posey, L. C. (1938). South. Med. J., 31, 761.

Potain, C., and Rendu, H. (1876). In Dictionnaire Encyclopédique des Sciences Médicales. 1st series, 18, p. 619, Paris.

Rannels, H. W., and Propst, H. J. (1937). J. Tech. Methods, 17, 113.

Roberts, J. T. (1937). J. Tech. Methods, 17, 108.

Rokitansky, C. (1852). A manual of Pathological Anatomy, IV, p. 251. Translation by G. E. Day. New Sydenham Society, London.

Routier, D., and Escalle, J. E. (1943). Arch. Mal Coeur, 36, 59.

Schafer, M. (1859). In Canstatt's Jahresbericht for 1859, Vol. II, p. 100.

Selzer, A., Carnes, W. H., Noble, C. A., Higgins, W. H., and Holmes, R. O. (1948). Amer. J. Med., $6,3$.

de Senac, J. B. (1749). Traité de la Structure de Caur, de son Action, et de ses Maladies, Vol. II, p. 404, Paris.

Swan, C., Tostevin, A. L., Moore, B., Mayo H., and Black, G. H. B. (1943). Med. J. Aust., 2, 201.

- (1944). J. Path. Bact., 56, 289.

Szypulski, J. T. (1937). J. Tech. Methods, 17, 119.

Taussig, H. B. (1947). Congenital Malformations of the Heart, p. 169. The Commonwealth Fund, New York.

Terplan, K., and Sanes, S. (1936). J. Tech. Methods, 15, 86.

Tuley, H. E., and Moore, J. W. (1917). Amer. J. Dis. Child., 13, 426.

Traube, L., quoted by Potain and Rendu (1876).

Usumoto, S. (1925). Dtsch. Arch. klin. Med., 147, 159.

Wardrop, J. (1851). The Nature and Treatment of the Diseases of the Heart, p. 219. London.

Wesselhoeft, C. (1949). New Engl. J. Med., 240, 258.

Wood, P. (1950). Brit. med. J., 2, 639 and 693. 